\title{
Co-Seismic Displacements of the 1992 Landers Earthquake Sequence
}

\author{
by K. W. Hudnut, Y. Bock, M. Cline, P. Fang, Y. Feng, J. Freymueller, X. Ge, \\ W. K. Gross, D. Jackson, M. Kim, N. E. King, J. Langbein, S. C. Larsen, \\ M. Lisowski, Z.-K. Shen, J. Svarc, and J. Zhang
}

\begin{abstract}
We present co-seismic displacement vectors derived from Global Positioning System (GPS) measurements of 92 stations in southern California. These GPS results are combined with five well-determined GPS displacement vectors from continuously tracking stations of the Permanent GPS Geodetic Array, as well as line-length changes from USGS Geodolite and two-color laser trilateration observations, to determine a self-consistent set of geodetic data for the earthquake. These combined displacements are modeled by an elastic dislocation representation of the primary fault rupture planes. On average, the model residuals are about twice the estimated measurement errors.
\end{abstract}

\section{Introduction}

The eastern Mojave shear zone (EMSZ) had been characterized on the basis of geodetic data prior to the seismic events of 1992 (Sauber et al., 1986; Savage et al., 1990). This tectonic element transfers $\sim 8 \mathrm{~mm} / \mathrm{yr}$ of displacement from the Salton Trough to the Owens Valley (Savage et al., 1990). The most recent VLBI results (Clark et al., 1987; Ma et al., 1992; Ryan et al., 1993) appear consistent with the trilateration studies, apparently leaving only 1 to $2 \mathrm{~mm} / \mathrm{yr}$ of relative plate motion to be accommodated in the southern Basin and Range if the NUVEL-1 relative plate motion model (DeMets et al., 1990) is correct.

Many geodetic sites were remeasured following the Joshua Tree earthquake $\left(M_{w}=6.1\right)$ on 23 April 1992. This event occurred just as the regional 1992 Inter-County survey, conducted by Caltech (in cooperation with County survey agencies), was completed. Caltech and UCLA groups from the Southern California Earthquake Center (SCEC) remeasured Global Positioning System (GPS) stations across the Joshua Tree rupture zone, and along the southern San Andreas fault. The USGS remeasured their Joshua Tree trilateration network and their GPS stations within the Joshua Tree net and in the Coachella monitor net. These activities were undertaken on the chance that the Joshua Tree event was a foreshock (though admittedly we were most concerned at the time about a larger event on the San Andreas fault).

The Landers mainshock $\left(M_{w}=7.3\right)$ and Big Bear aftershock $\left(M_{w}=6.2\right)$ occurred on 28 June 1992. Again, GPS and trilateration remeasurements were carried out by numerous agencies. University researchers from Caltech, UCLA, Scripps, and Stanford, as well as USGS researchers and County surveyors, all participated in extensive remeasurements for several weeks after the
Landers event. Much of the work within the first several weeks concentrated on near-field stations (within $\sim 50$ $\mathrm{km}$ of the surface ruptures), and along the San Andreas fault. Following these initial field programs, an extensive remeasurement of the regional Caltrans High Precision Geodetic Network (HPGN) and parts of the InterCounty and Salton Trough-Riverside County (STRC) networks was performed in a cooperative survey by Caltrans, the National Geodetic Survey (NGS), and SCEC during late 1992 and early 1993 . These surveys provided co-seismic displacement data for stations throughout southern California. The results of all of these surveys before and after the Landers earthquake sequence are presented in this article. We have brought together the results of many people's efforts to provide a complete data set. Subsets of the Landers co-seismic geodetic displacement data have been presented previously (Hudnut et al., 1992; Bock et al., 1993a; Blewitt et al., 1993; Murray et al., 1993; Miller et al., 1993).

Our work within a few days following the Landers mainshock provided initial displacement field maps using seismological and geological information about the earthquake source. It was readily evident that the Landers sequence had produced displacements measurable with GPS over a large area (Fig. 1). The area affected by $>1-\mathrm{cm}$ displacement encompasses most of southern California. Within a few months after the earthquakes, preliminary displacements at geodetic stations close to the fault rupture were seen to be roughly consistent with our early modeling. Since then, we have improved our results for near-field stations and processed data from many more stations (including some in the near field and many in the intermediate distance range of 50 to $150 \mathrm{~km}$ from the surface ruptures). 


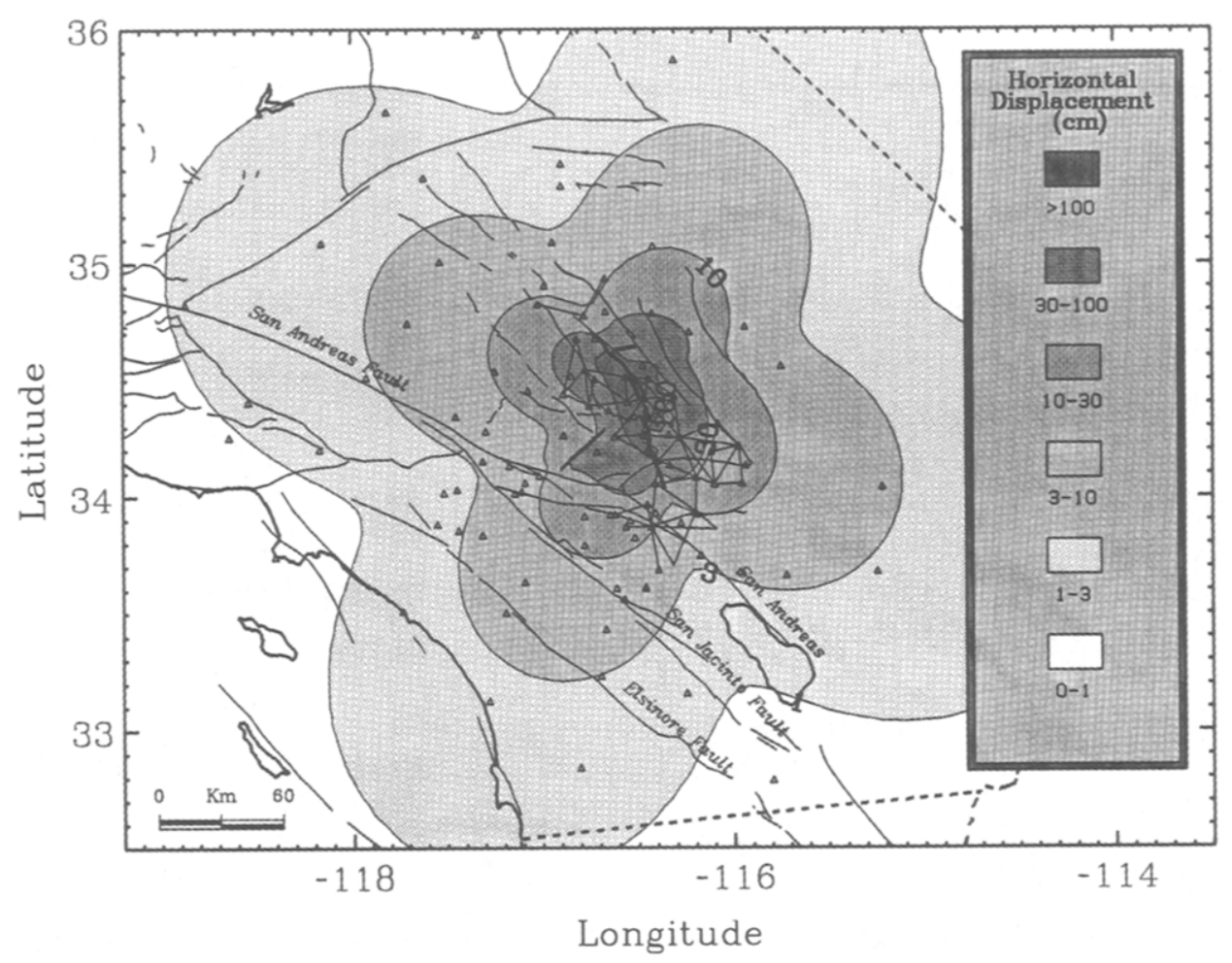

Figure 1. The modeled co-seismic horizontal static displacement field associated with the 28 June 1992 Landers earthquake sequence. This earthquake sequence produced near-field displacements of up to several meters between sites on opposite sides of the rupture zone, and detectable crustal deformation throughout most of southern California. Geodetic stations are shown as follows: open triangles are GPS stations for which co-seismic displacement vectors are estimated in this article, including the PGGA stations (Bock et al., 1993a; Blewitt et al., 1993), and triangles connected by lines indicate the USGS trilateration networks in the vicinity of the Landers event (Murray et al., 1993). The modeled fault geometry is shown in bold lines. The model parameters from which this displacement field was calculated are presented in Table 4.

Far-field GPS displacements were modeled successfully based on seismological and geological source information (Bock et al., 1993a; Blewitt et al., 1993). Also, Murray et al. (1993) used the USGS trilateration data to model the slip distribution in more detail. In the current study, we use an improved and more complete GPS data set, and merge our GPS results with trilateration measurements from Murray et al. (1993). We also present additional trilateration data from USGS two-color laser measurements. We present these new results and provide a refined interpretation of the observed displacements in terms of a revised faulting model for the earthquake sequence.

Several other articles (Freymueller et al., 1994; Wald and Heaton, 1994; Hudnut and Larsen, 1993) model the geodetic data by other methods. The model presented here is relatively simple. Slip distribution models are useful for revising estimates of stress change on other faults in the region (e.g., Simpson and Harris, 1994; Harris and Simpson, 1992; Jaume and Sykes, 1992; Stein et $a l ., 1992)$, and for modeling displacements of other geo- detic stations through models such as the NGS's REDEAM program (Snay et al., 1987) and more recent Time-Dependent Positioning (TDP) program (Snay and Herbrechtsmeier, 1994). We expect that additional data to be collected, as well as improvements in error analysis and modeling methods, may contribute to future improvements of the source model. In particular, it will be important to accurately account for secular and postseismic deformation at GPS sites where more than a few months' time elapsed between pre-earthquake and postearthquake measurements, and where postseismic strain rates were high (e.g., Shen et al., 1994; Bock et al., 1994).

\section{Data and Analysis}

The pre-earthquake and postearthquake GPS data, from which we have derived co-seismic displacement estimates, are from numerous sources and were collected with a variety of GPS equipment (Table 1; Figs. 2 and 3; Appendix, Table A1). These data have been analyzed 
Table 1

GPS Displacements; Observations, Errors, and Model Residuals

\begin{tabular}{|c|c|c|c|c|c|c|c|c|c|c|}
\hline $\begin{array}{c}\text { Site } \\
\text { Name }\end{array}$ & $\begin{array}{l}\text { North* } \\
(\mathrm{cm})\end{array}$ & $\begin{array}{l}\text { Norhh } \\
\text { Error }^{8} \\
(\mathrm{~cm})\end{array}$ & $\begin{array}{l}\text { North } \\
\text { Residual } \\
\text { (cm) }\end{array}$ & $\begin{array}{l}\text { East }^{\dagger} \\
(\mathbf{c m})\end{array}$ & $\begin{array}{l}\text { East } \\
\text { error } \\
(\mathrm{cm})\end{array}$ & $\begin{array}{c}\text { East } \\
\text { Residual" } \\
\text { (cm) }\end{array}$ & $\begin{array}{l}\text { Vertical* } \\
\text { (crn) }\end{array}$ & $\begin{array}{l}\text { Vertical } \\
\text { Error" } \\
\text { (cm) }\end{array}$ & $\begin{array}{c}\text { Vertical } \\
\text { Residual" } \\
\text { (cm) }\end{array}$ & $\begin{array}{l}\text { Result } \\
\text { Source }\end{array}$ \\
\hline PIN1 & 4.6 & 0.1 & -0.1 & 1.4 & 0.2 & -0.4 & 1.0 & 0.6 & -0.4 & SIO-N \\
\hline GOLD & -1.5 & 0.1 & 0.1 & -0.8 & 0.2 & 0.2 & 0.6 & 0.6 & 0.2 & SIO-N \\
\hline JPLI & 0.3 & 0.1 & -0.2 & -1.5 & 0.2 & -0.2 & 0.0 & 0.0 & 0.4 & SIO-N \\
\hline $\mathrm{SIO} 2$ & 1.3 & 0.2 & -0.2 & 1.0 & 0.3 & 0.4 & 1.0 & 0.8 & 0.5 & SIO-N \\
\hline VNDP & 0.5 & 0.2 & 0.4 & -0.4 & 0.3 & -0.1 & 0.4 & 0.5 & 0.5 & SIO-N \\
\hline 0618 & 1.4 & 1.4 & 1.1 & -0.1 & 3.0 & 0.9 & 6.2 & 8.0 & 6.5 & SIO-G \\
\hline 0704 & 0.4 & 1.0 & 0.0 & -5.4 & 2.4 & -4.3 & -0.2 & 6.5 & 0.2 & SIO-G \\
\hline 0705 & -1.0 & 0.9 & -1.9 & -3.0 & 0.8 & 0.3 & -1.7 & 6.3 & -0.7 & USGS-G \\
\hline 0802 & -7.2 & 1.1 & -4.2 & 0.3 & 2.0 & 1.5 & -0.4 & 6.3 & -1.4 & SIOG-G \\
\hline 0803 & -12.0 & 0.9 & -3.0 & -1.0 & 1.7 & 1.6 & 0.5 & 5.2 & -1.9 & SIO-G \\
\hline 0805 & -0.3 & 1.0 & -1.7 & -3.3 & 2.2 & 0.2 & -2.7 & 6.0 & -1.6 & SIO-G \\
\hline 0806 & -1.4 & 1.0 & -2.0 & -1.5 & 2.4 & 0.1 & 0.0 & 6.4 & 0.5 & SIO-G \\
\hline 0808 & -9.8 & 1.0 & -4.2 & -1.8 & 2.0 & -2.2 & -0.7 & 5.9 & -1.3 & SIO-G \\
\hline 0809 & -5.5 & 1.1 & -4.2 & 1.4 & 2.2 & 0.6 & 0.7 & 6.6 & 0.8 & SIO-G \\
\hline 0811 & -4.3 & 1.1 & -3.9 & -1.2 & 2.2 & -1.9 & -2.2 & 6.4 & -2.0 & SIO-G \\
\hline 0818 & 5.6 & 0.8 & 0.0 & 0.6 & 0.7 & -0.6 & -3.3 & 5.6 & -4.6 & USGS-G \\
\hline 0819 & 3.3 & 1.2 & 1.5 & -1.5 & 1.0 & -1.6 & 0.9 & 8.1 & 0.5 & USGS-G \\
\hline 0821 & 5.0 & 0.8 & 0.0 & 2.3 & 0.7 & 0.6 & 4.0 & 5.8 & 2.5 & USGS-G \\
\hline 1106 & 1.9 & 0.8 & 0.4 & -1.4 & 0.8 & -1.9 & 0.4 & 6.0 & -0.2 & USGS-G \\
\hline 1107 & 3.0 & 0.8 & 1.0 & 0.1 & 0.7 & -0.7 & 4.9 & 5.9 & 4.2 & USGS-G \\
\hline 1108 & 3.1 & 0.8 & 0.4 & -4.3 & 0.7 & -5.2 & -5.4 & 6.1 & -6.3 & USGS-G \\
\hline 1109 & 1.0 & 1.0 & -0.4 & -0.3 & 1.0 & -0.9 & -1.1 & 7.1 & -1.5 & USGS-G \\
\hline 1110 & -0.3 & 1.2 & -0.7 & 0.4 & 1.0 & -0.4 & 3.4 & 8.4 & 3.4 & USGS-G \\
\hline 1111 & -1.6 & 1.3 & -1.3 & 1.3 & 2.7 & 0.2 & -1.7 & 8.0 & -1.5 & SIO-G \\
\hline 1112 & -3.0 & 1.3 & -2.6 & -0.5 & 2.6 & -1.5 & -2.6 & 7.7 & -2.3 & SIO-G \\
\hline 1113 & -5.5 & 1.0 & -4.6 & 5.9 & 0.9 & 2.9 & -0.7 & 7.1 & -0.1 & USGS-G \\
\hline 1114 & -4.2 & 1.3 & -3.2 & 2.5 & 2.4 & -0.4 & -1.8 & 7.7 & -1.0 & SIO-G \\
\hline 6050 & -48.0 & 3.7 & 4.9 & 49.5 & 9.5 & 3.6 & 17.9 & 111.8 & 16.8 & STAN \\
\hline 6052 & 2.9 & 5.2 & -7.0 & -37.4 & 7.4 & 3.8 & 6.1 & 107.9 & 11.6 & STAN \\
\hline 6054 & 129.3 & 3.5 & -20.7 & 10.1 & 8.0 & 26.2 & -7.9 & 85.1 & -14.2 & STAN \\
\hline 6056 & 66.3 & 3.6 & 7.4 & -9.7 & 7.0 & 5.3 & 5.4 & 74.9 & 5.2 & STAN \\
\hline 6058 & 33.3 & 5.3 & 3.2 & 13.6 & 9.0 & -0.9 & 3.7 & 93.6 & -1.2 & STAN \\
\hline 6060 & -28.4 & 7.4 & -5.9 & 42.9 & 9.9 & -3.6 & 14.4 & 159.7 & 11.0 & STAN \\
\hline 7000 & 15.4 & 5.7 & 6.6 & -95.5 & 17.7 & -57.0 & 48.4 & 179.8 & 48.5 & STAN \\
\hline 7001 & -120.2 & 3.0 & -9.8 & 38.3 & 5.3 & 12.7 & 8.7 & 69.3 & 12.1 & STAN \\
\hline 7002 & -115.8 & 3.1 & 25.1 & 57.4 & 7.7 & 36.1 & 7.0 & 69.7 & 14.4 & STAN \\
\hline 7007 & -22.7 & 3.5 & -5.5 & 1.7 & 6.2 & 4.6 & 9.4 & 81.9 & 6.8 & STAN \\
\hline AMBO & -7.4 & 1.1 & -4.5 & 4.6 & 2.2 & 0.9 & 0.4 & 6.2 & 1.2 & SIO-G \\
\hline ANZA & 7.6 & 1.1 & 2.3 & -0.6 & 0.9 & -2.4 & -3.8 & 8.0 & -5.5 & USGS-G \\
\hline BEAR & 9.9 & 0.3 & 1.1 & -4.2 & 0.3 & 2.3 & -18.3 & 1.7 & -19.0 & USGS-G \\
\hline BLAC & -3.4 & 0.4 & -2.1 & 2.1 & 0.4 & -0.8 & -0.4 & 2.5 & 0.5 & USGS-G \\
\hline BOUC & 5.0 & 0.9 & 1.7 & 1.4 & 0.8 & 0.1 & 3.8 & 6.5 & 2.7 & USGS-G \\
\hline BRIN & 3.5 & 1.4 & -1.5 & -1.8 & 4.9 & -2.8 & 5.6 & 66.0 & 4.5 & STAN \\
\hline CABA & 19.8 & 1.5 & 4.9 & 6.1 & 1.5 & -0.1 & -4.3 & 9.9 & -8.1 & USGS \\
\hline CAJO & -0.7 & 0.9 & -2.2 & -6.1 & 0.7 & -1.5 & -1.4 & 5.7 & -0.2 & USGS-G \\
\hline CHAP & -0.4 & 1.5 & -2.9 & -0.1 & 1.5 & 2.3 & 8.3 & 10.5 & 8.6 & USGS-O \\
\hline CHER & 15.4 & 2.1 & 3.9 & 4.1 & 1.5 & -0.7 & -14.2 & 13.2 & -16.7 & USGS-O \\
\hline $\mathrm{COCH}$ & -1.8 & 2.4 & -2.1 & 3.8 & 2.7 & 0.6 & -0.9 & 12.6 & -0.7 & USGS-O \\
\hline CRAF & 6.6 & 2.1 & 0.9 & 2.7 & 1.7 & 2.4 & & & & UCLA \\
\hline CRIS & -4.4 & 1.2 & -3.3 & 2.7 & 2.4 & -0.2 & -2.4 & 7.0 & -1.4 & SIO-G \\
\hline DASH & 5.1 & 1.1 & 0.4 & 1.8 & 2.2 & -0.4 & 1.5 & 6.0 & -0.1 & SIO-G \\
\hline DUMP & -10.0 & 5.8 & 9.7 & -28.4 & 16.8 & -22.2 & 37.3 & 188.4 & 36.3 & STAN \\
\hline EDM2 & 5.0 & 1.6 & -4.5 & 5.4 & 1.7 & 1.1 & 6.7 & 11.1 & 4.7 & USGS-G \\
\hline ENDD & -5.0 & 1.3 & -4.6 & 0.0 & 2.5 & -1.3 & -4.8 & 7.6 & -4.3 & SIO-G \\
\hline GAP & -0.7 & 0.9 & -1.2 & 3.2 & 2.1 & 0.0 & -7.0 & 25.6 & -6.9 & STAN \\
\hline GARN & 14.4 & 0.3 & -0.6 & -5.5 & 0.3 & -0.3 & -0.4 & 1.9 & -3.8 & USGS-G \\
\hline GODW & -7.5 & 0.8 & -2.0 & 9.8 & 0.7 & -2.5 & -3.2 & 5.5 & -0.1 & USGS-G \\
\hline HECT & -32.4 & 0.5 & -4.9 & -6.8 & 0.5 & 1.0 & 4.2 & 3.6 & 0.0 & USGS-G \\
\hline HIGH & 3.0 & 1.5 & -1.0 & 0.6 & 1.2 & 2.7 & -3.2 & 10.2 & -3.4 & USGS-O \\
\hline INAS & 26.7 & 0.8 & 1.1 & 10.1 & 0.8 & -1.2 & -0.6 & 4.8 & -4.5 & USGS-G \\
\hline INDO & 13.4 & 0.9 & 3.2 & 2.5 & 0.7 & -1.7 & 5.8 & 6.2 & -8.7 & USGS-G \\
\hline
\end{tabular}


Table 1-Continued

\begin{tabular}{|c|c|c|c|c|c|c|c|c|c|c|}
\hline $\begin{array}{c}\text { Site } \\
\text { Name }\end{array}$ & $\begin{array}{c}\text { North* } \\
(\mathrm{cm})\end{array}$ & $\begin{array}{l}\text { North } \\
\text { Enror } \\
(\mathrm{cm}) \\
\end{array}$ & $\begin{array}{c}\begin{array}{c}\text { North } \\
\text { Residual" } \\
\text { (cm) }\end{array} \\
\end{array}$ & $\begin{array}{l}\text { East' } \\
\text { (cm) }\end{array}$ & $\begin{array}{c}\text { East } \\
\text { error }^{8} \\
(\mathrm{~cm})\end{array}$ & $\begin{array}{c}\text { East } \\
\text { Residual" } \\
(\mathrm{cm})\end{array}$ & $\begin{array}{c}\begin{array}{c}\text { Vertical } \\
(\mathrm{cm})\end{array} \\
\end{array}$ & $\begin{array}{l}\text { Verrical } \\
\text { Error" } \\
(\mathbf{c m}) \\
\end{array}$ & $\begin{array}{c}\text { Vertical } \\
\text { Residual" } \\
\text { (cm) }\end{array}$ & $\begin{array}{l}\text { Result } \\
\text { Source }\end{array}$ \\
\hline INYO & -1.6 & 1.0 & -1.9 & -0.6 & 2.4 & 0.3 & -2.1 & 6.3 & -1.8 & SIO-G \\
\hline JURU & 0.8 & 1.1 & -1.2 & 1.3 & 1.8 & 2.1 & -2.3 & 36.5 & -2.4 & STAN \\
\hline L290 & -1.0 & 2.4 & -0.7 & 3.2 & 2.0 & 3.7 & & & & UCLA \\
\hline LAST & 3.4 & 0.9 & 0.2 & -0.5 & 0.8 & -1.7 & 0.1 & 6.3 & -0.8 & USGS-G \\
\hline LAZY & 169.7 & 0.3 & -4.5 & -10.3 & 0.3 & 7.0 & -14.9 & 2.0 & -13.5 & USGS-G \\
\hline LIMP & 7.8 & 2.4 & 6.2 & 1.2 & 2.0 & 1.7 & & & & UCLA \\
\hline LUCS & -0.2 & 1.2 & -7.4 & -25.1 & 1.0 & -0.8 & & & & UCLA \\
\hline MATH & 2.3 & 0.9 & -0.1 & -1.2 & 0.8 & -1.7 & -4.0 & 6.5 & -4.6 & USGS-G \\
\hline MAUM & -166.7 & 0.5 & 6.6 & 57.6 & 0.5 & 2.4 & 11.3 & 3.4 & 11.2 & USGS-G \\
\hline MDAY & 0.1 & 1.8 & -1.2 & -2.6 & 1.5 & 1.2 & -1.3 & 12.0 & 0.0 & USGS \\
\hline MEEK & 65.6 & 0.6 & 4.5 & 23.9 & 0.7 & 3.1 & 2.3 & 4.1 & -3.1 & USGS-G \\
\hline MILL & 5.7 & 2.4 & -1.7 & 5.8 & 2.1 & 6.1 & 7.0 & 15.0 & 5.4 & USGS \\
\hline MILU & 0.4 & 1.0 & -1.8 & -4.3 & 1.9 & 0.6 & -10.2 & 35.1 & -9.1 & STAN \\
\hline NIGU & 2.0 & 1.0 & 0.6 & -1.3 & 0.8 & -1.9 & -5.5 & 6.8 & -6.0 & USGS-G \\
\hline OCOT & -0.3 & 0.9 & -0.6 & -2.3 & 0.9 & -2.7 & 4.3 & 6.2 & 4.3 & USGS-G \\
\hline ONYX & 33.9 & 2.3 & -3.3 & 23.5 & 5.2 & 3.5 & 9.5 & 68.6 & 4.9 & STAN \\
\hline PARK & -2.3 & 4.2 & -0.6 & 1.2 & 3.4 & 1.7 & & & & UCLA \\
\hline PAVE & -3.4 & 2.5 & -2.8 & 2.1 & 2.1 & 0.9 & & & & UCLA \\
\hline PEAR & -0.9 & 0.9 & -1.7 & -2.1 & 0.8 & 0.6 & 0.3 & 6.3 & 1.2 & USGS-G \\
\hline PINY & 5.1 & 1.2 & 0.4 & -1.3 & 1.0 & -3.1 & -3.9 & 8.7 & -5.3 & USGS-G \\
\hline POIN & -0.2 & 0.9 & -3.9 & -14.0 & 0.7 & 0.5 & 2.6 & 6.1 & 5.8 & USGS-G \\
\hline PORT & -1.3 & 1.8 & -1.9 & 1.6 & 1.5 & 3.4 & & & & UCLA \\
\hline PVER & 1.5 & 0.6 & 1.0 & -3.8 & 0.5 & -3.6 & -0.1 & 3.9 & -0.1 & USGS-G \\
\hline RESO & 4.6 & 0.7 & 0.0 & 3.1 & 2.0 & 1.0 & -0.7 & 24.9 & -1.9 & STAN \\
\hline ROCH & 5.6 & 0.2 & -0.3 & 3.2 & 0.5 & 1.2 & 1.9 & 6.7 & 0.1 & STAN \\
\hline ROD2 & -3.8 & 3.3 & -3.2 & 2.1 & 2.7 & 1.9 & & & & UCLA \\
\hline ROSA & 6.6 & 1.2 & 3.2 & -1.7 & 0.9 & -3.2 & -6.4 & 8.0 & -7.5 & USGS-G \\
\hline ROUN & -1.4 & 27 & -1.7 & 6.8 & 2.4 & 7.6 & 8.2 & 16.2 & 8.5 & USGS \\
\hline SAND & -30.9 & 0.4 & 1.0 & 41.1 & 0.5 & 2.5 & -1.0 & 2.9 & 1.2 & USGS-G \\
\hline SANO & 2.2 & 1.5 & 0.5 & 3.5 & 1.5 & 4.3 & 3.9 & 10.5 & 3.9 & USGS \\
\hline SOAP & 2.7 & 0.7 & 0.9 & -6.5 & 0.8 & 0.0 & -6.4 & 5.2 & -4.9 & USGS-G \\
\hline STIM & 4.5 & 1.5 & 1.8 & -4.0 & 1.3 & 6.1 & 0.8 & 7.6 & 3.5 & USGS-G \\
\hline THOU & -13.5 & 5.7 & -14.7 & 11.7 & 5.4 & 6.3 & 2.4 & 23.1 & 2.4 & USGS \\
\hline TOM2 & 19.7 & 0.9 & 2.1 & 5.0 & 0.8 & -2.3 & -1.0 & 5.8 & -5.1 & USGS-G \\
\hline VIEW & -9.5 & 0.4 & -6.8 & 7.0 & 0.4 & -0.8 & -6.6 & 3.0 & -5.5 & USGS-G \\
\hline WIDE & 8.9 & 0.3 & -1.7 & 4.3 & 0.3 & -1.4 & 1.7 & 1.9 & -0.1 & USGS-G \\
\hline
\end{tabular}

*North-north/south displacement component: north is positive, south is negative.

${ }^{\dagger}$ East-east/west displacement component: east is positive, west is negative.

"Vertical-up/down displacement component: up is positive, down is negative. Blank if not estimated.

${ }^{5}$ North, East, and Vertical Error-one-sigma error estimate in displacement component.

INorth, East, and Vertial Residuals-residual modeled displacement based on 29-segment elastic dislocation model.

using different processing techniques, and have been compiled and indexed at the SCEC archiving facility. The main GPS data resources for this article came from the following surveys (Table A1 contains further specifics).

\section{Pre-Earthquake}

1. Caltech and County Surveyor's Inter-County 1992 survey: dual-frequency L2-codeless data; 6-hr site occupations.

2. The 1991 HPGN survey: dual-frequency L2-codeless data; 6-hr site occupations.

3. San Bernardino County Geographic Information Management System (GIMS) network: single-frequency data; $<2$-hr site occupations.
4. Caltech and UCLA: dual-frequency L2-codeless data; 6-hr site occupations, and 24-hr occupations for about 1 week following Joshua Tree earthquake.

5. The USGS: L2-codeless dual frequency data; 6 -hr site occupations.

\section{Postearthquake}

1. Scripps, UCLA, Stanford, and Caltech (with Riverside Co. Flood Control Dist.): dual-frequency L2codeless data; 6- and 24-hr site occupations for several weeks after the earthquake. Short sessions $(<4$ hr) on San Bernardino "single-frequency" sites in some cases. Occasional 24-hr session reoccupations be- 
Far \& Intermediate-Field Geodetic Displacements

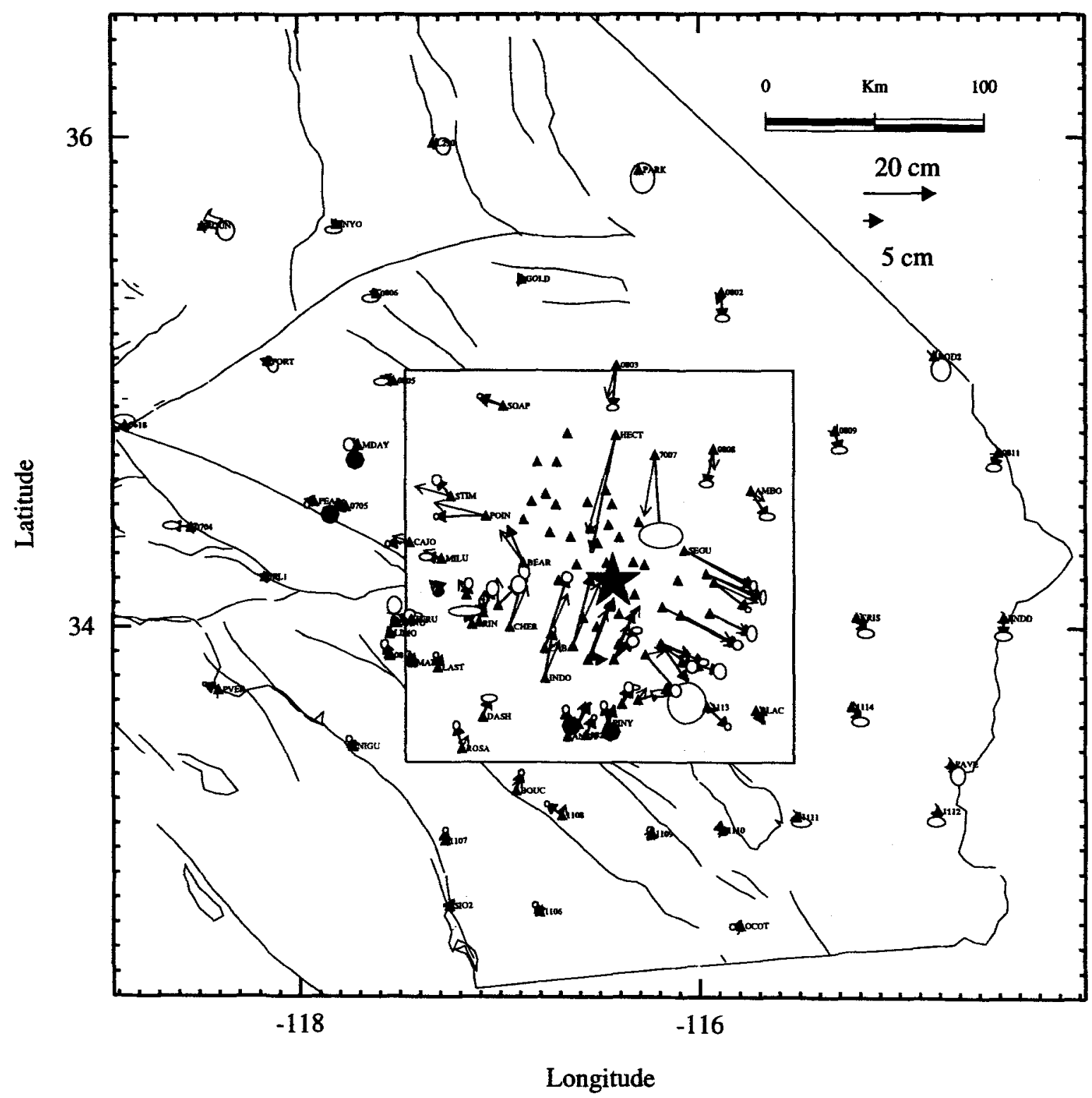

Figure 2. Far-field and intermediate-field displacements, their one-sigma error ellipses, and model predictions for GPS sites. Much of the mis-fit between modeled and observed displacement at far-field sites is attributed to secular deformation (up to $\sim 2 \mathrm{yr}$ in some cases). Displacement vectors for near-field stations are not shown at some sites because of scale, but the site locations are indicated for reference (see Fig. 3). Box indicates the region shown in Figure 3. The Landers mainshock epicenter is indicated by a star, and geodetic sites are indicated by triangles.

tween August and October 1992 by UCLA for postseismic studies.

2. The USGS: dual-frequency L2-codeless data; 6-hr site occupations.

3. Caltrans, SCEC, NGS, and Counties: dual-frequency L2-codeless data; 6-hr site occupations. Major regional resurvey from November 1992 to January 1993.
The analysis of these data sets makes use of the continuous data and products provided by the Permanent GPS Geodetic Array (PGGA) in southern California (Bock et $a l .$, 1993a). These products include daily precise satellite ephemerides, PGGA station positions and velocities, and cycle-slip clean PGGA and global tracking data (Bock et al., 1993b). 


\section{Near-Field Geodetic Displacements}

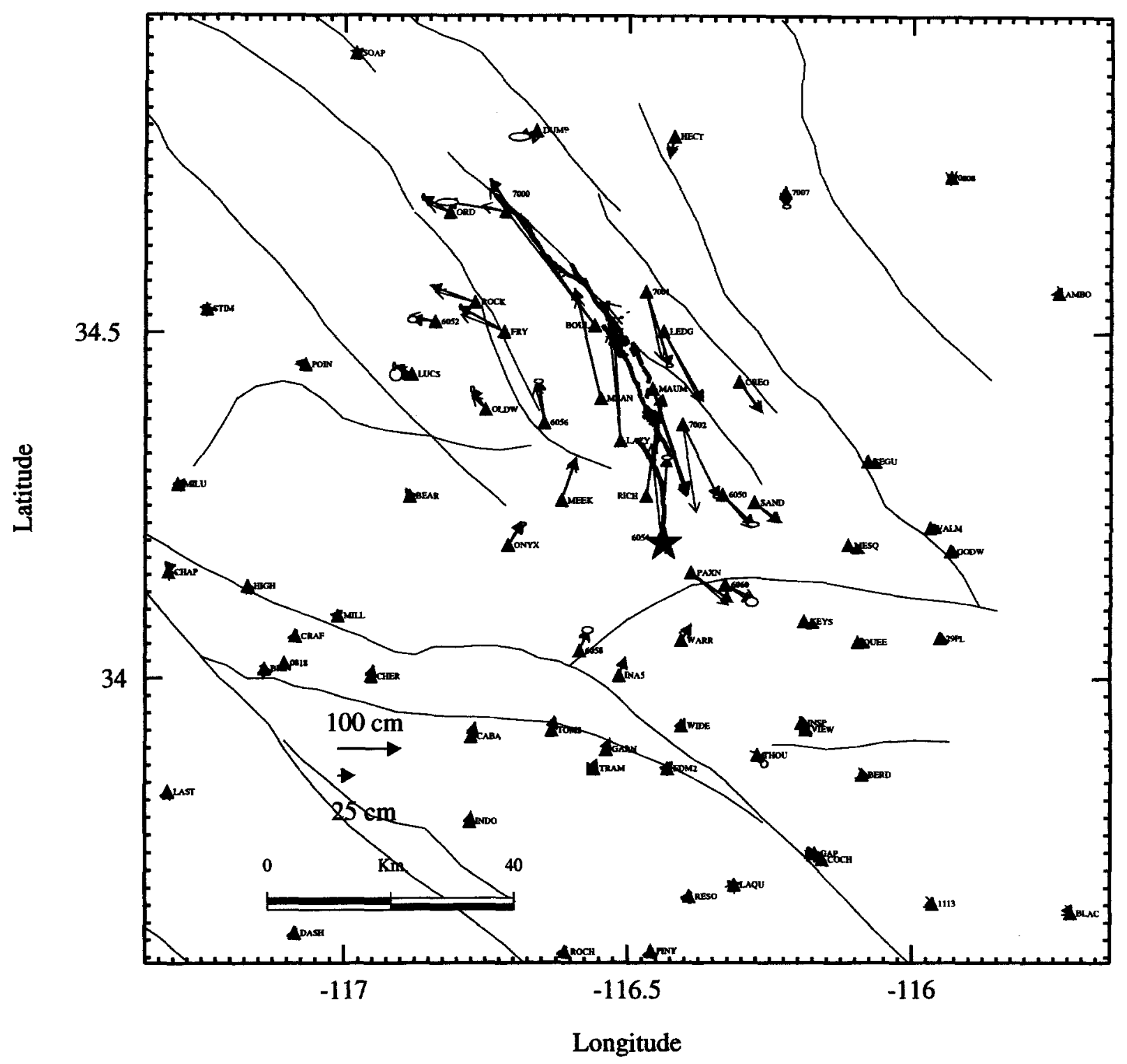

Figure 3. Intermediate and near-field displacements, their one-sigma error ellipses, and model predictions for GPS sites and USGS trilateration stations. Note the change in scale from Figure 2. Map of surface faulting in the Landers sequence is from Sieh et al. (1993).

In addition to GPS observations, we have adjusted the line-length changes in the Mojave network for secular strain rates between the latest pre-earthquake geodolite survey in 1982.5, and 1992.8 (Table 2a), the time of the GPS remeasurement of those lines after the earthquake. We show the USGS trilateration measurements (Murray et al., 1993) in the form of displacement vectors, including the secular adjustments. We recalculated the displacement vectors for the trilateration network stations based on our revised GPS displacements of four stations that were surveyed both by trilateration and GPS; this only affects the conversion from line-length changes to displacements. The trilateration results are comparable in accuracy to the best-quality GPS data (Savage and Prescott, 1973). The GPS and trilateration data have been merged into a self-consistent and uniform set of displacement vectors and errors (Table 1 and $2 b$ ). Furthermore, we show the line-length change data from the twocolor laser trilateration networks and include these data in our modeling (Table 3 and Appendix, Table A2).

\section{Methods for Determination of GPS Displacements}

Several comments apply to all of the GPS results, and we begin by discussing these general points. We 
Table 2A

Line-Length Modifications Based on Uniform Secular Strain in the USGS Mojave Trilateration Network (1982) to (1992)*

\begin{tabular}{|c|c|c|c|c|c|}
\hline Station 1 & Station 2 & $\begin{array}{c}\text { Observed } \\
\text { Line-Length } \\
\text { Change }^{\dagger}(\mathrm{cm})\end{array}$ & $\begin{array}{l}\text { Estimated } \\
\text { Secular } \\
\text { Change (cm) }\end{array}$ & $\begin{array}{c}\text { Estimated } \\
\text { Co-Seismic } \\
\text { Change (cm) }\end{array}$ & $\begin{array}{l}\text { One-Sigma } \\
\text { Error }^{\dagger}(\mathrm{cm})\end{array}$ \\
\hline Boulder & Ledge & 262.40 & 0.93 & 261.47 & 0.53 \\
\hline Boulder & Means & 68.80 & -0.94 & 69.74 & 0.54 \\
\hline Boulder & Rock & -134.80 & 1.58 & -136.38 & 0.70 \\
\hline Creole & Ledge & -56.50 & 0.62 & -57.12 & 0.59 \\
\hline Fry & Means & -51.40 & 0.76 & -52.16 & 0.68 \\
\hline Fry & Old Woman & -5.10 & -1.01 & -4.09 & 0.56 \\
\hline Fry & Rock & -10.30 & 0.07 & -10.37 & 0.46 \\
\hline Ledge & Maumee & 56.30 & -0.76 & 57.06 & 0.50 \\
\hline Ledge & Means & -137.90 & -0.24 & -137.66 & 0.60 \\
\hline Lucerne So. & Old Woman & -1.30 & 0.81 & -2.11 & 0.57 \\
\hline Lucerne So. & Ord & 5.90 & -2.12 & 8.02 & 0.87 \\
\hline Lucerne So. & Rock & -17.10 & -0.33 & -16.77 & 0.61 \\
\hline Maumee & Means & 34.00 & 0.62 & 33.38 & 0.49 \\
\hline Means & Old Woman & -4.40 & 1.47 & -5.87 & 0.68 \\
\hline Old Woman & Rock & -2.00 & -1.36 & -0.64 & 0.65 \\
\hline Ord & Rock & -10.70 & -0.97 & -9.73 & 0.60 \\
\hline
\end{tabular}

*All pre-earthquake data collected by USGS Geodolite trilateration survey in June 1982. All postearthquake data collected by USGS GPS survey with codeless dual-frequency Ashtech M-XII receivers in November 1992. Data processed with the Bernese software.

'Observed change and one-sigma errors are unmodified from Murray et al. (1993).

Table 2B

USGS Geodolite Trilateration Data

\begin{tabular}{lrrrr}
\hline & \multicolumn{4}{c}{ Computed Displacements } \\
\cline { 2 - 5 } \multicolumn{1}{c}{ Site } & \multicolumn{1}{c}{$\begin{array}{c}\text { North } \\
\text { Name }\end{array}$} & $\begin{array}{c}\text { North Error } \\
(\mathrm{cm})\end{array}$ & $\begin{array}{c}\text { East } \\
(\mathrm{cm})\end{array}$ & $\begin{array}{c}\text { East Error } \\
(\mathrm{cm})\end{array}$ \\
\hline 29PA & 12.0 & 1.4 & -5.5 & 2.2 \\
BERD & 10.7 & 1.8 & -2.6 & 2.2 \\
CREO & 35.4 & 0.7 & -48.3 & 0.7 \\
EDM2 & 6.5 & 1.5 & 8.1 & 0.9 \\
INSP & 12.2 & 1.4 & -5.3 & 1.0 \\
KEYS & 22.0 & 1.0 & -10.6 & 0.8 \\
LAQU & 6.5 & 2.6 & 1.9 & 1.0 \\
MAUM & 57.0 & 0.5 & -168.0 & 0.4 \\
MEEK & 23.6 & 0.5 & 66.9 & 0.5 \\
MESQ & 23.8 & 1.0 & -11.5 & 1.2 \\
PAXN & 65.2 & 0.7 & -46.6 & 0.6 \\
QUEE & 16.2 & 1.3 & -8.4 & 1.3 \\
RICH & 26.0 & 0.5 & 161.0 & 0.6 \\
SAND & 41.6 & 0.4 & -30.9 & 0.4 \\
SEGU & 19.5 & 1.0 & -9.8 & 1.4 \\
VALM & 16.0 & 0.8 & -6.5 & 2.0 \\
WARR & 15.2 & 1.1 & 24.0 & 0.7 \\
BOUL & -169.0 & 1.3 & 235.0 & 2.0 \\
LEDG & 62.6 & 1.1 & -11.0 & 0.6 \\
MEAN & -41.4 & 0.8 & 176.0 & 1.8 \\
FRY & -71.6 & 1.9 & 40.1 & 4.5 \\
LUCS & -28.8 & 2.1 & 12.4 & 6.6 \\
OLDW & -21.8 & 2.9 & 32.2 & 4.8 \\
ORD & -43.5 & 2.1 & 24.2 & 4.9 \\
ROCK & -70.3 & 0.2 & 26.7 & 1.2 \\
\hline & & & &
\end{tabular}

present the GPS displacements with their standard errors in the north, east, and up components (Table 1), computed relative to the Jet Propulsion Lab (JPL) tracking site in Pasadena, $155 \mathrm{~km}$ distant from the earthquake epicenter. The JPL site was chosen as our reference point because data from this tracking receiver were included in nearly all of the GPS solutions analyzed (62 of the $\mathbf{7 2}$ GAMIT solutions), far more than any other regional site. The displacement of the JPL site has been separately determined with respect to a reference frame defined by the coordinates of the global tracking network stations as $0.34 \pm 0.13 \mathrm{~cm}$ north and $1.47 \pm 0.24 \mathrm{~cm}$ west (Bock et al., 1993a).

Our use of the JPL station as a reference leads to two problems that require brief explanation. First, the station was displaced co-seismically, and we chose not to explicitly correct our displacement vectors for this small effect. This could cause a slight shift in the reference frame of the GPS displacements that would contribute systematically to misfits in modeling the data, particularly in the east-west component. We have partially accounted for this in the modeling by solving for translation and rotation of the GPS data with respect to the trilateration data, but we prefer not to make the static shift offset in our presentation of the GPS data (Table 1) as this does not represent the actual results we used in modeling the data. Also, we find that the mis-fit to the 
east-west component is actually a bit better than to the north-south component, so we feel this effect was negligible in this case. Second, we know that secular deformation is present in some of the GPS data analyzed, particularly the pre-earthquake HPGN data set, versus the postearthquake NGS/Caltrans/SCEC resurvey of those stations. These surveys are separated by up to $2 \mathrm{yr}$, and many of the displacement vectors determined from comparison of these two surveys are for stations that had less than $10-\mathrm{cm}$ displacement. Hence, we are sure this forms a significant and systematic contribution to model misfits in the intermediate-range data ( $\sim 50$ to $150 \mathrm{~km}$ from

Table 3

Two-Color Trilateration Data, Error, and Residuals

\begin{tabular}{|c|c|c|c|}
\hline Line & Data (cm) & Enor (cm) & Residuals (cm) \\
\hline green-pf1 & -0.018 & 0.076 & 0.01 \\
\hline green-pf2 & 0.143 & 0.041 & -0.02 \\
\hline green-pf2a & 0.116 & 0.051 & -0.01 \\
\hline green-pf3 & 0.205 & 0.058 & 0.03 \\
\hline green-pf4a & 0.480 & 0.074 & 0.20 \\
\hline green-pf5 & 0.613 & 0.081 & 0.25 \\
\hline green-pf6 & -0.044 & 0.056 & -0.05 \\
\hline green-sugar & 0.183 & 0.064 & 0.06 \\
\hline table-radio & 0.658 & 0.087 & 0.06 \\
\hline table-red & -0.389 & 0.091 & -0.31 \\
\hline table-roadcut & 0.726 & 0.112 & 0.21 \\
\hline table-rosa & 0.283 & 0.140 & 0.24 \\
\hline table-terwil & -0.119 & 0.137 & -0.20 \\
\hline table-tule & 1.096 & 0.136 & 0.30 \\
\hline openvw-anza & 0.873 & 0.095 & 0.34 \\
\hline openvw-bull & -0.296 & 0.078 & -0.21 \\
\hline openvw-cary & 0.537 & 0.162 & 0.06 \\
\hline openvw-cravens & 0.951 & 0.088 & 0.31 \\
\hline openvw-fobes & 1.095 & 0.103 & 0.20 \\
\hline openvw-scrunge & 0.620 & 0.126 & -0.02 \\
\hline openvw-howy & 0.576 & 0.099 & 0.11 \\
\hline lime-ward & -0.251 & 0.054 & -0.03 \\
\hline lime-swan & -0.045 & 0.043 & 0.07 \\
\hline lime-pinyon & -0.009 & 0.072 & 0.01 \\
\hline lime-neefus & 0.010 & 0.032 & 0.12 \\
\hline lime-llano & 0.015 & 0.046 & 0.07 \\
\hline lime-lewis & -0.166 & 0.053 & -0.05 \\
\hline lime-lepage & -0.386 & 0.057 & -0.13 \\
\hline lime-largo & -0.264 & 0.050 & 0.03 \\
\hline lime-calef & 0.234 & 0.099 & 0.30 \\
\hline lime-bird & -0.433 & 0.060 & -0.12 \\
\hline lime-bigrock & 0.087 & 0.062 & 0.05 \\
\hline lime-punch & -0.018 & 0.039 & -0.01 \\
\hline butte-adobe & -0.125 & 0.169 & 0.06 \\
\hline butte-mirage & 0.019 & 0.166 & -0.01 \\
\hline butte-monday & 0.059 & 0.161 & 0.00 \\
\hline butte-moody & -0.192 & 0.194 & -0.10 \\
\hline butte-hivista & -0.251 & 0.157 & -0.18 \\
\hline butte-playa & -0.760 & 0.321 & -0.45 \\
\hline butte-bluerock & -0.990 & 0.214 & -0.58 \\
\hline butte-park & -0.330 & 0.129 & -0.21 \\
\hline butte-saddle & -0.021 & 0.148 & -0.15 \\
\hline butte-sand & -0.100 & 0.168 & 0.03 \\
\hline butte-hansen & -0.240 & 0.233 & -0.09 \\
\hline butte-east & -0.434 & 0.196 & -0.35 \\
\hline
\end{tabular}

the fault rupture). As seen in Figure 2, the modeled displacements in some cases go in opposite directions to the observed displacement vectors, and the observed displacements are approximately in the expected direction for secular deformation. The effect of secular deformation is worse when we use JPL as the reference site than it would be if we used Goldstone or Mojave as our reference, but these stations' tracking data are less continuous (Goldstone) and of lower quality (Mojave) than the JPL data.

The results of the different analysis groups were compared statistically in order to best determine which results should be included in Table 1 and used for modeling the slip distribution of the Landers sequence. For a large number of stations, co-seismic displacements were redundantly determined by the Scripps, Stanford, UCLA, and USGS groups. In analyzing the different groups' results, each vector component was compared between groups by differencing component pairs, and dividing this difference by each group's stated error in that component. This allowed us to identify any discrepancies in the results between different groups. It was useful also in identifying which groups' error estimates were evidently too low or too high. This process was done iteratively in order to arrive at a single set of displacement results (Table 1) that we deem most accurate and with best represented errors. The only systematic difference noticed between results of the different groups' analyses, which appears to have resulted from a difference in fiducial constraints, was corrected by applying a translation to the Scripps results to mesh these with the USGS GLOBK results. The results in Table 1 are mainly from three sources: the Scripps and USGS solutions obtained by GLOBK, and the Stanford group's estimates for the stations that used GIMS single-frequency data for the preearthquake data set. Details of the processing methods used by each group are given in the Appendix.

\section{Modeling}

We use a simple model that fits the data as well as possible for an a priori fault geometry based closely upon surface faulting and aftershock seismicity. The elastic dislocation modeling that we use has proven to be successful for modeling other earthquakes. Elastic dislocation theory can be used to compute the displacements at a given site from the slip distribution model (e.g., Savage and Hastie, 1966; Mansinha and Smylie, 1971; Okada, 1985; Harris and Segall, 1987; Segall and Harris, 1987). Modeling was performed with the GINV (inversion) and DISL (forward modeling) software that incorporate a combination of algorithms from these references (Larsen, 1991). The model we present in Table 4 is based upon inversion of all the data sets presented here: The GPS data were input to these inversions as displacement vector components and errors, and the 
Table 4

Model Parameters

\begin{tabular}{lccrrr}
\hline \multicolumn{1}{c}{ Model Segment* } & Latitude & Longitude & Length (km) & Azimuth & Slip (cm) \\
\hline Camp Rock A & 34.6791 & -116.7070 & 8.140 & -43.28 & 0 \\
Camp Rock B & 34.6344 & -116.6619 & 4.963 & -62.04 & 200 \\
Emerson A & 34.5913 & -116.6114 & 8.671 & -36.92 & 270 \\
Emerson B & 34.5549 & -116.5634 & 3.439 & -57.40 & 640 \\
Emerson C & 34.5319 & -116.5432 & 2.887 & -50.11 & 580 \\
Emerson D & 34.5126 & -116.5240 & 2.680 & -51.47 & 255 \\
Emerson E & 34.4873 & -116.4996 & 4.512 & -51.28 & 480 \\
Emerson F & 34.4538 & -116.4741 & 4.370 & -64.83 & 360 \\
Transfer A & 34.5099 & -116.5331 & 2.698 & -89.65 & 375 \\
Transfer B & 34.4881 & -116.5148 & 3.359 & -89.69 & 130 \\
Transfer C & 34.4157 & -116.4677 & 4.581 & -98.76 & 345 \\
Homestead Valley A & 34.5037 & -116.5389 & 1.730 & -50.72 & 150 \\
Homestead Valley B & 34.4853 & -116.5239 & 3.225 & -58.77 & 240 \\
Homestead Valley C-1 & 34.4521 & -116.5032 & 4.761 & -65.34 & 225 \\
Homestead Valley C-2 & 34.4133 & -116.4816 & 4.750 & -65.35 & 615 \\
Slip Gap & 34.3864 & -116.4597 & 2.945 & -42.43 & 90 \\
Homestead Valley D & 34.3704 & -116.4483 & 1.576 & -92.61 & 140 \\
Homestead Valley E & 34.3412 & -116.4369 & 5.383 & -66.29 & 380 \\
Kickapoo & 34.3375 & -116.4521 & 5.796 & -96.25 & 320 \\
Johnson Valley A & 34.3288 & -116.4707 & 4.753 & -53.89 & 0 \\
Johnson Valley B & 34.2973 & -116.4481 & 3.465 & -66.97 & 410 \\
Johnson Valley C & 34.2654 & -116.4389 & 3.918 & -84.85 & 280 \\
Johnson Valley D & 34.2299 & -116.4380 & 4.011 & -92.76 & 190 \\
Johnson Valley E & 34.1937 & -116.4341 & 4.141 & -77.32 & 310 \\
Paxton & 34.1506 & -116.4076 & 7.156 & -67.58 & 130 \\
Eureka Peak A & 34.1027 & -116.3849 & 4.282 & -70.31 & 0 \\
Eureka Peak B & 34.0587 & -116.3673 & 6.050 & -72.52 & 10 \\
Big Bear & 34.2042 & -116.7833 & 28.000 & 42.00 & -44 \\
Iron Ridge & 34.6337 & -116.5625 & 11.614 & 9.66 & -23 \\
\hline
\end{tabular}

*All model segments dip vertically from the surface to $10-\mathrm{km}$ depth.

${ }^{\dagger}$ Azimuth is given in degrees counterclockwise from due cast.

geodolite and two-color trilateration data were input as line-length changes and errors. We then forward modeled the slip distribution given in Table 4 to obtain the model displacements. We did not use positivity or surface slip observation constraints on the primary fault breaks in the inversions that guided the forward model result that we present.

The slip distribution (Table 4; Fig. 4) is representative of the main Landers sequence, but does not precisely fit some of the very near-field stations $(<5 \mathrm{~km}$ away from fault ruptures). We speculate that in areas close to the surface fault breaks, details of fault geometry and slip variation with depth (particularly in the shallowest part of the fault) are important, and anelastic deformation likely occurred. We chose a model with even slip distribution with depth, and slip extending down to $10-\mathrm{km}$ depth along the entire fault. We included fault segments along the main faults that ruptured at the surface in the Landers event (as well as the Paxton segment, which had no surface slip but which did have aftershocks), and an additional two subsidiary faults representing the Iron Ridge fault [on which $23 \mathrm{~cm}$ of leftlateral slip was observed at the surface (Hart et al., 1993)] and the Big Bear fault.
We have simplified the mapped surface fault traces into 27 planar segments (Fig. 4). In places, these model fault segments overlap along strike, mimicking the observed surface faulting (Sieh et al., 1993). The complexity in our model is confined to along-strike variation in fault segment strike, as well as overlap between fault segments and several intersecting faults. Our representation of the Landers sequence is, therefore, a complex dislocation model. The geometry of the fault segments defined in our model (Fig. 1) were determined precisely, based upon digitized maps of field mapping (e.g., Fig. 4 based on Sieh et al., 1993). Coordinates of the fault segments were converted from the North American Datum (NAD) 1927 to NAD 1983 to match reference frames between the model and the coordinates of the geodetic stations. The geodetic data resolve along-strike variations in slip much better than they resolve variations in slip with depth (for minimally constrained models such as ours). Because we determine a uniform slip value on each horizontal segment, our results are consistent with smaller or larger values within particular depth ranges (in slip models that allow variable slip with depth) as long as those average to the same value we obtain, within errors. 


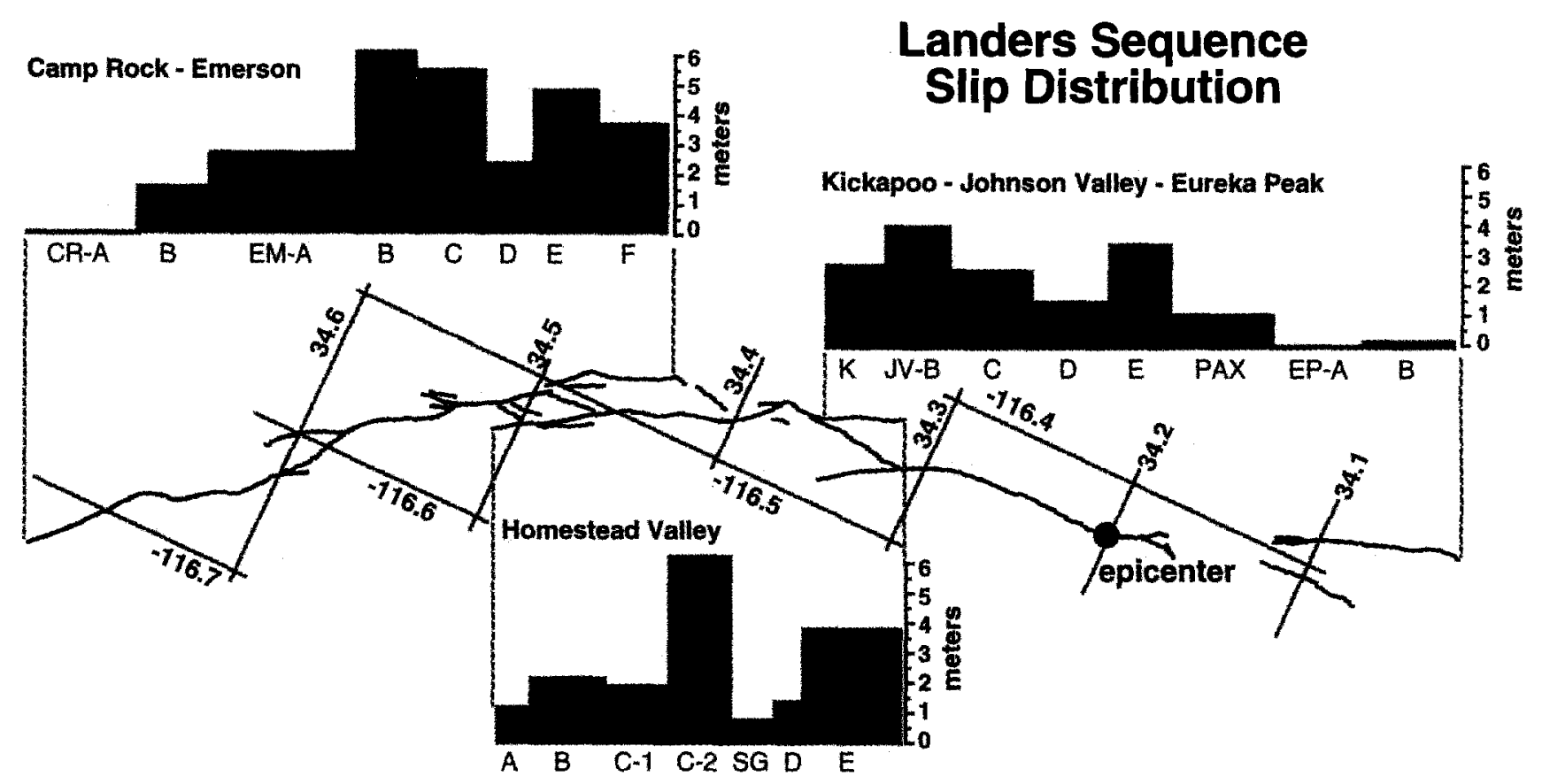

Figure 4. Slip distribution for the Landers earthquake sequence main fault ruptures obtained by modeling the geodetic data by dislocations in an elastic halfspace. Slip on each segment represents average slip between the surface and 10$\mathrm{km}$ depth. The model is given in Table 4. Labels on segments of the faults correspond to Table 4 as follows: Camp Rock $=\mathrm{CR}$, Emerson $=\mathrm{EM}$, Homestead Valley $=$ HV, Slip Gap $=$ SG, Kickapoo $=K$, Johnson Valley $=J V$, Paxton $=$ PAX, and Eureka Peak = EP.

Table 5

Summary of Model Mis-Fit RMS Residuals

\begin{tabular}{ccc}
\hline & \multicolumn{2}{c}{ (Observed-Model)/Error } \\
\cline { 2 - 3 } Data Type & Number of Data & RMS Mis-Fit \\
\hline GPS & & \\
east/west & 97 & 1.90 \\
north/south & 97 & 2.46 \\
up/down & 89 & 0.57 \\
Geodolite* & 60 & 2.99 \\
Two-Color* & 45 & 1.39 \\
All Data & (weighted) & 1.84 \\
\hline
\end{tabular}

*Geodolite and two-color trilateration data errors and residuals are based upon line-length changes.

Statistically, the slip distribution model does not fit the geodetic data satisfactorily. Subsets of the data have RMS residuals as shown in Table 5. Values near one would be expected for a model that represented the data well. Contributions to mis-fits at near-field stations may include anelastic effects, such as co-seismic deformation, that did not occur on the modeled faults, as suggested by Murray et al. (1993). The main contribution to mis-fits at intermediate and far-field stations is most likely secular strain (that has not been removed or corrected). Our mis-fitting of the geodolite trilateration subset of the data can be explained by reasons suggested by
Murray et al. (1993). We have only marginally improved over their model residuals in the present effort (theirs was 4.5 on average, ours is 3 ).

As noted by Murray et al. (1993), a large suite of possible slip distribution models can fit the data. We have attempted a variety of model parameterizations (varied fault geometry, allowing slip variation with depth, applying constraints to the surface faulting data, etc.). Although we have found that it is possible to fit the data better by allowing variable slip with depth, this added complexity in the model increases the parameter space considerably. Introduction of variable slip with depth requires the introduction of additional constraints in order to maintain a well-posed inversion, and as such goes beyond the level of modeling detail we choose to treat here.

Other sources of mis-fits between the model and data are interseismic or secular deformation (as evident in Fig. 2), and potentially postseismic deformation (e.g., Shen et al., 1994; Bock et al., 1994). Neither of these effects is expected to be $>6 \mathrm{~cm}$ at any site, and the effects are not accounted for in the present study. These problems manifest themselves, however, by slightly degrading the fit between our model and the data, most notably at intermediate and far-field stations. Another effect that is expected to be relatively small is the displacement at the fixed station JPL. For distant stations (especially ones with small errors), this is a quantifiable factor in mis- 
fitting the data that we have not taken into consideration explicitly.

It is also possible that we are underestimating the true errors in some GPS data. In the displacements that are based upon single-frequency data prior to the Landers sequence, for example, estimates at some stations disagreed between the UCLA and Stanford groups by amounts much larger than the stated errors. We have attempted to resolve these problems. Many of the singlefrequency stations are close to faults, and difficult to model. This may be because the displacement field near the faults is complicated, or because we are underestimating errors in the single-frequency solutions. For example, Peltzer et al. (1993) found that the SAR interferometry results did not agree well with our GPS results at a few of these sites, and it was suggested that the errors in the single-frequency GPS pre-earthquake solutions may be erroneous at those few sites. Because the errors at these sites are much larger than errors for sites with better-quality GPS data, they are weighted such that they do not greatly influence the model results we present.

\section{Summary of Results and Discussion}

The results of our analyses and comparisons between different groups' GPS and trilateration results have been reduced into Tables 1,2 , and 3 , as described in the Appendix. The main results of our work are shown in Figures 2 and 3. We have newly estimated co-seismic displacements for 92 GPS stations throughout the southern California region. The displacements detailed in Tables 1 and 2B are presented in Figures 2 and 3, showing the observed displacements and associated errors, and the modeled displacements for comparison. Figure 2 shows the intermediate- to far-field displacements, and Figure 3 shows the near- to intermediate-field station displacements.

By inspection of the observed and modeled displacement vectors for each site in Figures 2 and 3, and by comparison to Figure 1, one may understand and appreciate the impressive displacement field produced by this earthquake sequence. This displacement field was measured by high-precision geodetic measurements presented here and also in Bock et al. (1993a, b); Blewitt et al. (1993); Murray et al. (1993); and Miller et al. (1993). The present article combines the results from several groups to add an extensive new set of GPS coseismic displacement vectors, as well as refine certain aspects of previously reported results. We present documentation of the large body of GPS data that were used to determine these displacements.

We also present an elastic dislocation model that is used to interpret the full set of GPS displacement and trilateration line-length data. This model provides the best fit to the geodetic data for the fault geometry we used
(Table 4; Figs. 4 and 5). It is not, however, statistically satisfactory for reasons that may actually represent interesting geophysical implications. Unmodeled complexity in the displacement field near the fault traces that ruptured, significant off-fault deformation that is unmodeled, uncorrected secular deformation, and a lack of accounting for variable slip with depth are all suggested as explanations for the difficulties encountered in arriving at a model that fits the data acceptably in a statistical sense.

Our results indicate a total moment of $1.03 \times 10^{27}$ dyne-cm for the Landers sequence. Other estimates of total moment range from $0.79 \times 10^{27}$ to $1.10 \times 10^{27}$ dyne-cm (e.g., Kanamori et al., 1992;. Murray et al., 1993; Sieh et al., 1993). If we consider the Paxton, Johnson Valley, and Kickapoo fault segments to have ruptured in the first subevent of the Landers mainshock (Kanamori et al., 1992), we estimate a moment for that subevent of $0.23 \times 10^{27}$ dyne- $\mathrm{cm}$. For the second subevent, we obtain a moment between $0.65 \times 10^{27}$ and $0.75 \times 10^{27}$ dyne-cm, depending on whether or not the Iron Ridge model fault slipped co-seismically during the Landers mainshock. For comparison, the seismologically determined moments for the first and second subevents are $0.19 \times 10^{27}$ and $0.61 \times 10^{27}$ dyne-cm, respectively. Furthermore, if we consider the Eureka Peak fault to have ruptured in the $M_{w}=5.7$ aftershock that occurred approximately $3 \mathrm{~min}$ after the Landers mainshock (Sieh et al., 1993), we obtain $M_{w}=5.3$ for that event. Partial rupture of the Paxton segment may have occured before or during this aftershock. For the Big Bear event $\left(M_{w}=6.2\right)$, we constrained slip in our model to that seismological moment. Taken together, these moment comparisons indicate overall similarities between the geodetic and seismological results for the Landers sequence.

In our slip distribution model, the gross features recognized by seismological and geological investigations are also observed. Two slip maxima occur in zones where the surface fault traces step-over from the Johnson Valley to the Homestead Valley fault, and from the Homestead Valley to the Emerson fault. These two slip maxima are separated by a relative slip minima that we term a "slip gap," centered at $34.38^{\circ} \mathrm{N}$. For comparison, the seismologic, geologic, and the present geodetic slip distribution model are overlain in Figure 5. In the seismological results (Kanamori et al., 1992), the slip gap is centered slightly farther to the north than we obtain. The geological evidence for the slip gap is a short $(<3$ $\mathrm{km}$ ) section of the Homestead Valley fault along which right-lateral slip diminished to zero, but where the vertical displacement (west side upthrown) reached 1 meter (Sieh et al., 1993). Our geodetic slip distribution model also makes clear that the largest amounts of slip occurred along the subparallel segments of the Homestead Valley and Emerson faults. Where the surface displacements were 


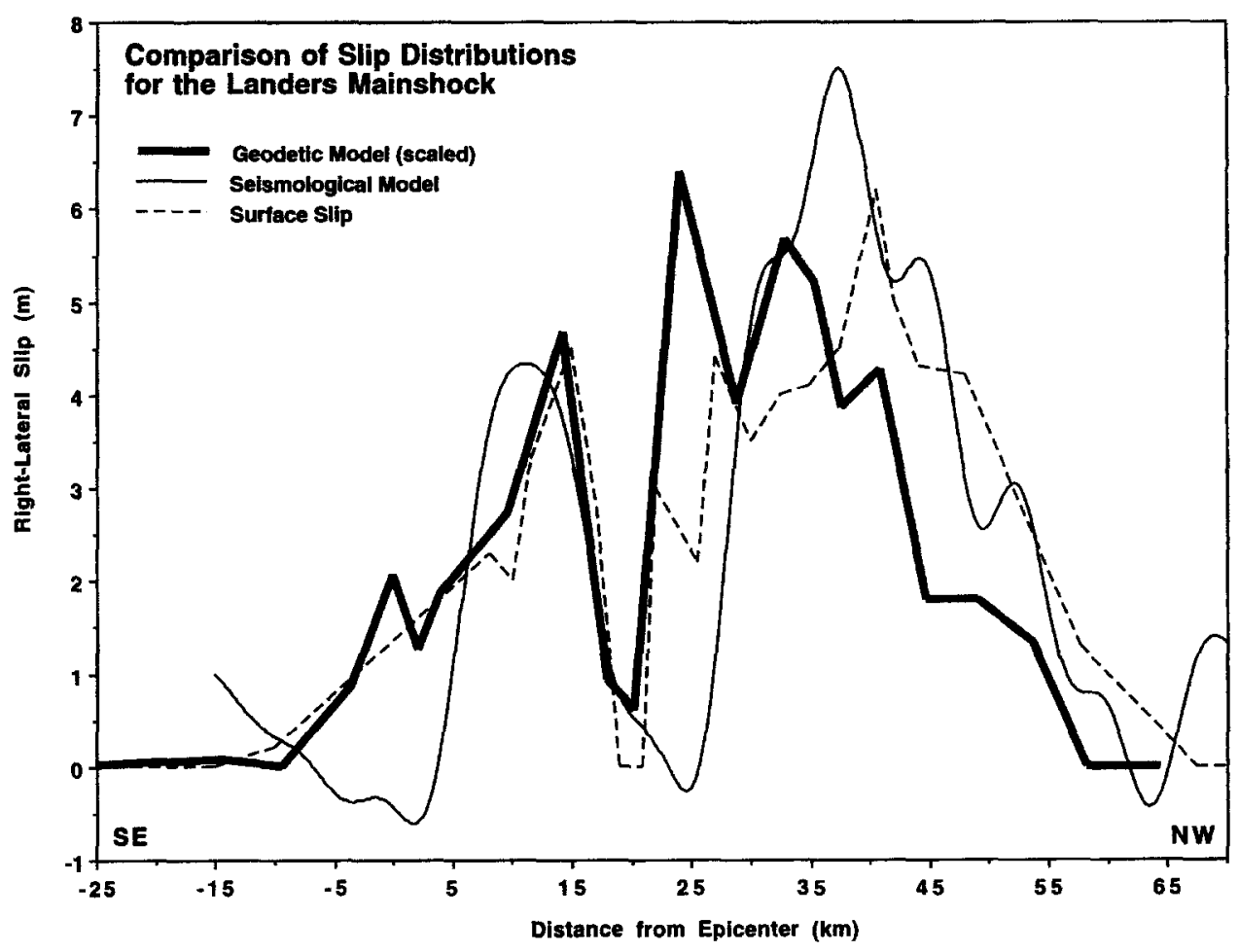

Figure 5. Comparison of slip distributions for the Landers earthquake obtained by different methods. All three slip distribution curves indicate two slip maxima separated by a slip gap. The geodetic model shown is a linearly interpolated version of the model given in Table 4. The seismological model and surface slip representation are modified slightly from Kanamori et al. (1992) and Sieh et al. (1993). The seismological and geodetic models represent average slip over the depth of faulting, whereas the surface slip does not. Note that our geodetic model is scaled by a factor of $2 / 3$ to account for the difference between the $10-\mathrm{km}$ depth used in this study and the $15-\mathrm{km}$ depth used by Kanamori et al. (1992).

highest, the geodetic modeling indicates relatively low slip (averaged over $10 \mathrm{~km}$ in depth), which implies that locally the high surface slip overlies considerably lower slip at depth along that segment (e.g., Hudnut and Larson, 1993).

From the approximate concurrence of seismological and geological slip distributions (Kanamori et al., 1992; Sieh et al., 1993), one might expect that the co-seismic geodetic data would also be consistent with this slip distribution. The seismological results are based on elastically radiated energy and the geological results are based on static surficial offsets (Sieh et al., 1993). Concurrence of moments estimated by these two methods implies that not much energy was lost in producing the static surficial offsets. Our model based on geodetic data is consistent in many respects with the seismological and geological results.

The southern and smaller of the two slip maxima is near 10 to $15 \mathrm{~km}$ north of the epicenter, the slip gap is near 20 to $25 \mathrm{~km}$ north of the epicenter, and the larger slip maxima is variously located between about 25 and $45 \mathrm{~km}$ north of the epicenter. Geodetic results indicate that the highest slip occurred in the step-over between the Homestead Valley and Emerson faults, farther south than is indicated by seismological and geological results. This result is more nearly in accord with the results of SAR interferometry (Massonet et al., 1993). We find lower slip at the location of the geologically observed slip maximum, perhaps indicating that high slip here was shallow, since we determine the average slip between the surface and $10-\mathrm{km}$ depth. At the southern slip maxima, it appears our result and the surface slip agree well, but the seismological peak is shifted to the south of ours. In contrast, from the slip gap to the northwest, the seismological result appears shifted northwards from our result. This could be explained by variable rupture velocity, as documented by Wald and Heaton (1994).

The proposed slip distribution model fits most of the trilateration and GPS data to within twice the standard deviations of the data for stations more than $\sim 5 \mathrm{~km}$ away from the ruptured faults, except for more distant sites where secular deformation contaminates the co-seismic geodetic signal at some sites. We show that precise geodetic networks over much of southern California were 
measurably affected by the Landers earthquake, and that these data may all be modeled with an adequately detailed slip distribution. We find no reason to invoke crustal heterogeneity (taken to mean layering of crustal material properties) to explain these data, as was suggested by Miller et al. (1993).

Using our geodetic model, we can compute the displacement at any geodetic point in the region, given the coordinates of that station. We have used preliminary versions of this model already to inform federal (NGS and U.S. Marine Corps), state (Caltrans), and county government surveying agencies on decisions about conducting their postearthquake surveys and performing geodetic datum re-adjustments. Such predictive modeling can be presented in map view as contoured displacements, as shown in Figure 1.

\section{Conclusions}

We integrate GPS and trilateration measurements to study the co-seismic crustal deformation associated with the Landers earthquake sequence. This article contributes GPS observations and two-color trilateration data that have not previously been published, and combines these with published GPS and geodolite trilateration results. We emphasize processing and analysis of the data, and provide estimates of displacement on 92 GPS stations in southern California. The slip model we obtain for the Landers sequence, based on these geodetic data, is consistent with some of the main features of the Landers slip distribution seen in seismological and geological results. We find two slip maxima separated by a slip minima. The northerly maximum is the larger of the two, and we locate this largest slip 5 to $10 \mathrm{~km}$ farther south than the slip maxima obtained seismologically or seen at the surface.

\section{Acknowledgments}

This study benefited from the field efforts of many people, including SCEC staff and UCLA and UCSD students, the staff of the USGS, engineers from the University Navstar Consortium (UNAVCO), and surveyors from state and county agencies. Bill Young of Riverside Co. Flood Control District and Jerry Stayner (County Surveyor, Riverside Co.), and also Larry Cotton (County Surveyor, San Bernardino Co.), gave much support in conducting the pre- and post-Landers field GPS surveys, and providing us with GPS data they collected prior to the Landers sequence for their own projects. Many GPS stations were provided by the Caltrans and NGS's HPGN project; these agencies also conducted extensive postearthquake field work and provided their data to the SCEC archive for use in this study. We would like to thank Larry Fenske, Bob Nelson, and John Fundus at Caltrans for access to the HPGN data. Some of the GPS stations used here were established in the STRC surveys led by Rob Reilinger at MIT. Reviews by D. Eberhart-Phillips, M. Murray, and J. Sauber helped to improve this manuscript. We especially thank M. Murray and D. Agnew for their efforts and their helpful and thorough commentaries. Funding for this work was from the USGS and NSF through the internal and external NEHRP programs and the SCEC. In part, this work was performed under the auspices of the Department of Energy by the Lawrence Livermore National Laboratory under contract W-7405-ENG-48. The work at Scripps is supported by NASA (NAGW-2641 and NAG 5-1917), NSF (EAR 92 08447), the Southern California Earthquake Center USGS cooperative agreement (14-08-00001-A0899), the USGS (1434-92G2196), and Caltrans (53N195). SCEC Contribution Number 94.

\section{References}

Blewitt, G., M. Heflin, K. Hurst, D. Jefferson, F. Webb, and J. Zumberge (1993). Absolute far-field displacements from the 28 June 1992 Landers earthquake sequence, Nature 361, no. 6410, 340-342.

Bock, Y., R. Abbot, C. Counselman, S. Gourevitch, and R. King (1986). Interferometric analysis of GPS phase observations, Man. Geod. 11, 282-288.

Bock, Y., D. Agnew, P. Fang, J. Genrich, B. Hager, T. Herring, K. Hudnut, R. King, S. Larsen, J.-B. Minster, K. Stark, S. Wdowinski, and F. Wyatt (1993a). Detection of crustal deformation related to the Landers earthquake sequence using continuous geodetic measurements, Nature 361, no. 6410, 337-340.

Bock, Y., J. Zhang, P. Fang, J. Genrich, K. Stark and S. Wdowinski (1993b). One year of daily satellite orbit and polar motion estimation for near real-time crustal deformation monitoring, in Developments in Astrometry and Their Impact on Astrophysics and Geodynamics, Kluwer Academic Publishers, Hingham, Massachusetts, 279-284.

Bock et al. (1994). Permanent GPS geodetic array in southern California: continuous monitoring of the crustal deformation cycle, J. Geophys. Res. (in press).

Clark, T., D. Gordon, W. Himwich, C. Ma, A. Mallama, and J. Ryan (1987). Determination of relative site motions in the western U.S. using Mark III VLBI, J. Geophys. Res. 92, 1274112750.

DeMets, C., R. G. Gordon, D. F. Argus, and S. Stein (1990). Current plate motions, Geophys. J. Int. 101, 425-478.

Dixon, T. H. (1991). An introduction to the Global Positioning System and some geological applications, Rev. Geophys. 29, 249276.

Dong, D. (1993). The horizontal velocity field in southern California from a combination of terrestrial and space-geodetic data, $P h . D$. Thesis, Massachusetts Institute of Technology, Cambridge, Massachusetts.

Dong, D. and Y. Bock (1989). GPS network analysis with phase ambiguity resolution applied to crustal deformation studies in California, J. Geophys. Res. 94, 3949-3966.

Feigl, K., R. King, and T. Jordan (1991). Geodetic measurement of tectonic deformation in the Santa Maria fold and thrust belt, California, J. Geophys. Res. 95, 2679-2699.

Feigl, K., D. Agnew, Y. Bock, D. Dong, A. Donnellan, B. Hager, T. Herring, D. Jackson, T. Jordan, R. King, S. Larsen, K. Larson, M. Murray, Z. Shen, and F. Webb (1993). Space geodetic measurement of corestal deformation in central and southern California, 1984-1992, J. Geophys. Res. v. 98, pp. 21,67721,712 .

Freymueller, J., N. E. King, and P. Segall (1994). The co-seismic slip distribution of the Landers earthquake, Bull. Seism. Soc. Am. 84, no. 3, 646-659.

Georgiadou, Y. and A. Kleusberg (1988). On the effect on ionospheric delay on geodetic relative GPS positioning, Manuscripta Geodetica 13, 1-8.

Harris, R. and P. Segall (1987). Detection of a locked zone at depth on the Parkfield segment of the San Andreas fault, J. Geophys. Res. 92, 7945-7962.

Harris, R. A. and R. W. Simpson (1992). Nature 360, 251.

Hart, E. W., W. A. Bryant, and J. A. Treiman (1993). Surface fault- 
ing associated with the June 1992 Landers earthquake, California, Calif. Geol. 46, no. 1, 10-16.

Herring, T. H., J. L. Davis, and I. I. Shapiro (1990). Geodesy by radio interferometry: the application of Kalman Filtering to the analysis of very long baseline interferometry data, $J$. Geophys. Res. 95, 12561-12583.

Hudnut, K., S. Larsen, M. Lisowski, K. Gross, J. Svarc, D. Jackson, Z. Shen, Y. Bock, and P. Fang (1992). Coseismic displacements in the Landers sequence: constraints from near-field geodetic data, EOS 73, no. 43, 365 .

Hudnut, K. W. and S. C. Larsen (1993). Slip distribution in the Landers, Calif., earthquake sequence determined from geodetic data, EOS 74, no. 43, 183.

Jaume, S. C. and L. R. Sykes (1992). Science 258, 1325

Kanamori, H., H.-K. Thio, D. Dreger, E. Hauksson, and T. Heaton (1992). Initial investigation of the Landers, California, earthquake of 28 June 1992 using TERRAscope, Geophys. Res. Lett. 19, no. 22, 2267-2270.

King, R. W., E. G. Masters, C. Rizos, A. Stolz, and J. Collins (1985). Surveying with Global Positioning System (GPS), Dummler, Bonn $128 \mathrm{pp}$.

Langbein, J. O., M. F. Linker, A. McGarr, and L. E. Slater (1982). Observations of strain accumulation across the San Andreas fault near Palmdale, California, with a two color geodimeter, Science 218, 1217-1219.

Langbein, J. O., M. F. Linker, A. F. McGarr, and L. E. Slater (1987). Precision of two-color measurements: results from 15 months of observation, J. Geophys. Res. 92, 11644-11656.

Langbein, J. (1989). Deformation of the Long Valley caldera, eastern California from mid-1983 to mid-1988: measurements using a two-color geodimeter, J. Geophys. Res. 94, 3833-3849.

Larsen, S. C. (1991). Geodetic measurements of deformation in southern California, Ph.D. Thesis, California Institute of Technology, Pasadena, 351 pp.

Ma, C., J. W. Ryan, and D. S. Caprette (1992). Crustal Dynamics Project Data Analysis--1991: VLBI Geodetic Results 1979-1990, NASA Technical Memorandum 104552.

Mansinha, L. and D. E. Smylie (1971). The displacement fields of inclined faults, Bull. Seism. Soc. Am. 61, 1433-1440.

Massonnet, D., M. Rossi, C. Carmona, F. Adragna, G. Peltzer, K. Feigl, and T. Rabaute (1993). The displacement field of the Landers earthquake mapped by radar interferometry, Nature 364, no. $6433,138-142$.

Miller, M., F. Webb, D. Townsend, M. Golombek, and R. Dokka (1993). Regional coseismic deformation from the June 28, 1992, Landers, Calif., earthquake: results from the Mojave GPS network, Geology 21, 868-872.

Murray, M., J. Savage, M. Lisowski, and Karl Gross (1993). Coseismic displacements: 1992 Landers, California earthquake, Geophys. Res. Lett. 20, 623-626.

Okada, Y. (1985). Surface deformation due to shear and tensile faults in a half-space, Bull. Seism. Soc. Am. 75, 1135-1154.

Peltzer, G., K. Feigl, D. Massonet (1993). Co-seismic surface displacement of the Landers earthquake sequence mapped by Radar interferometry, EOS 74, no. 43, 60.

Ryan, J. W., C. Ma, and D. S. Caprette (1993). NASA Space Geodesy Program-GSFC Data Analysis-1992: Final Report of the Crustal Dynamics Project-VLBI Geodetic Results 1979-1991, NASA Technical Memorandum 104572.

Sauber, J., W. Thatcher, S. Solomon (1986). Geodetic measurement of deformation in the Central Mojave Desert California, J. Geophys. Res. 91, 12683-12693.

Savage, J. and L. Hastie (1966). Surface deformation associated with dip-slip faulting, J. Geophys. Res. 71, 4897-4904.

Savage, J. C. and W. Prescott (1973). Precision of Geodolite measurements for determining fault movements, J. Geophys. Res. $78,6001-6008$.
Savage, J. C., M. Lisowski, and W. H. Prescott (1990). An apparent shear zone trending north-northwest across the Mojave desert into Owens Valley, eastern California, Geophys. Res. Lett. 17, no. $12,2113-2116$.

Segall, P. and R. Harris (1987). Earthquake deformation cycle on the San Andreas fault near Parkfield, California, J. Geophys. Res. 92, 10511-10525.

Sieh, K., L. Jones, E. Hauksson, K. Hudnut, D. Eberhart-Phillips, T. Heaton, S. Hough, K. Hutton, H. Kanamori, A. Lilje, S. Lindvall, S. McGill, J. Mori, C. Rubin, J. Spotila, J. Stock, H. K. Thio, J. Treiman, B. Wernicke, and J. Zachariasen (1993). Near-field investigations of the Landers earthquake sequence, April to July, 1992, Science 260, 171-176.

Shen, Z.-K., D.D. Jackson, Y. Feng, M. Cline, M. Kim, P. Fang, and Y. Bock (1994). Postseismic deformation following the Landers earthquake, California, 28 June 1992, Bull. Seism. Soc. Am. 84, no. 3, 780-791.

Simpson, R. and R. Harris, BSSA (in press).

Slater, L. E. and G. R. Huggett (1976). A multi-wavelength distance measuring instrument for geophysical experiments, $J$. Geophys. Res. 81, 6299-6306.

Snay, R. A., M. Cline, and E. Timmerman (1987). Project REDEAM: models for historical horizontal deformation, NOAA Technical Report NOS 125 NGS 42, U.S. Dept. of Commerce, Rockville, Maryland, 1987.

Snay, R. A. and E. Herbrechtsmeier (1994). The TDP-H91-CA model for historical horizontal deformation in California, Manuscripta Geodaetica (in press).

Stein, R., G. C. P. King, and J. Lin (1992). Change in failure stress on the S. San Andreas fault system caused by the $1992 M=7.4$ Landers earthquake, Science 258, 1328-1332.

Wald, D. J. and T. H. Heaton (1994). Spatial and temporal distribution of slip for the 1992 Landers, California earthquake, Bull. Seism. Soc. Am. 84, no. 3, 668-691.

\section{Appendix}

This Appendix contains details of the GPS and trilateration data processing and analysis, as well as tabulations of information regarding station coordinates and ancillary data for the sites used in this study. Additional data, such as the original GPS data, solution files, and descriptions to reach these survey stations are available from the SCEC archive or from the authors by request.

\section{Processing Methods}

Although the principles used in differential static positioning are similar (e.g., King et al., 1985; Dixon, 1991), we describe particulars of the methods used by our several distinct groups. The GPS data were processed as follows: (1) the SCEC analysis groups (UCSD, UCLA, Caltech) used the GAMIT software for all dual-frequency processing, and UCLA also processed the single-frequency data using GAMIT; (2) the USGS group used the GAMIT and Bernese softwares; and (3) the Stanford group used the GIPSY/OASIS II software for dual-frequency processing, and the Bernese software for the single-frequency data.

Processing of pre-earthquake single-frequency GPS data from the San Bernardino County Surveyor GIMS network by the UCLA and Stanford groups involved 
modified processing techniques. A limitation of singlefrequency GPS data is that one cannot cancel out the refraction component contributed by the ionosphere, as can be done with dual-frequency data, so this must be modeled. This leads to higher errors, especially in the vertical component. Furthermore, it is harder to estimate ambiguities (partly as a result of short observation sessions) and the data are harder to clean because there is only one phase observable. Although only a small portion of our GPS results come from stations with preearthquake single-frequency data, a disproportionate part of this discussion treats these results, since the processing methods are not as well known as for dual-frequency data processing.

GAMIT Dual- and Single-Frequency Solutions. The SCEC groups processed most of the pre-earthquake HPGN data (Scripps), much of the Inter-County 1992 survey data (UCLA and Caltech/USGS), most of the post-Joshua Tree data from the USGS, UCLA, and Caltech/USGS (UCLA and Caltech/USGS), and a large proportion of the post-Landers data, including the SCEC/NGS/Caltrans surveys (UCLA). Seventy-two daily solutions, processed with the GAMIT software by the Scripps, UCLA, and Caltech/USGS groups, were used to determine many of the displacements in Table 1. These were improved orbit solutions (that include global and regional sites) from the PGGA based on global and regional tracking data (e.g., Bock et al., 1993a). Orbits for all solutions have satellite positional accuracies of $<1 \mathrm{~m}$. We followed the wellestablished processing methods with GAMIT (e.g., Bock et al., 1986; Dong and Bock, 1989; Feigl et al., 1991; Bock et al., 1993a; Feigl et al., 1993).

Most of the GPS data used in this study are from dual-frequency, L2-codeless receivers at field sites. These data were generally decimated from 30 - to $120-\mathrm{sec}$ sampling to reduce computation time. Beginning with PGGA orbits, we processed data from global tracking network stations along with our local data to estimate corrections to the PGGA orbits. Positions of the fiducial tracking stations were constrained to their ITRF 1991 coordinates. For daily solutions, we first made station clock corrections to the phase data using pseudo-range measurements. Then the dual-frequency, double-differenced phase measurements were scaled and differenced to form the linear combination (LC) of L1 and L2 phase data (also known as L3 or ionosphere-free combination). The data were then fit by least squares to obtain a solution that minimizes residuals in LC. We solved for the local station positions, along with the tropospheric delay residuals, ambiguity integers, and satellite orbital parameters. An uncertainty of $10 \mathrm{~mm}$ was assumed for the phase data. Estimation of ambiguity integers for the phase data was achieved by rounding to integers whenever specified confidence limits were reached. We used bias-fixed solutions for the present analyses.
For the single-frequency data from the pre-earthquake survey of the San Bernardino County Surveyor's Office GIMS network, solutions were constrained by fixing the PGGA satellite orbits. Only local stations were processed, to estimate the interstation vectors. The single-frequency surveys performed prior to the earthquake were carried out by placing three receivers at field sites in each survey session. The stations were occupied in a leapfrog procession, such that one station's coordinates of the three could be taken as a priori information in determining the other two stations' coordinates. Data with a 30-sec sampling interval instead of 120-sec were used for single-frequency data processing. Carrier phase data uncertainty was assumed to be $50 \mathrm{~mm}$ for single frequency (compared to $10 \mathrm{~mm}$ for dual frequency). The larger uncertainty used for single-frequency data accounts for ionospheric disturbances.

GIPSY/OASIS II Dual- and Bernese Single-Frequency Solutions. The Stanford group analyzed pre-earthquake data from the Caltrans HPGN, the San Bernardino County Surveyor's Office GIMS network, the U.S. Geological Survey's GPS networks, and selected data from the Caltech and Counties' Inter-County network. Postearthquake data included all data collected by SCEC, Stanford, Scripps Institute of Oceanography, and the USGS in the first 20 days after the earthquake. Except for the GIMS survey and the USGS pre-earthquake surveys, all data were analyzed in a manner very similar to the work of the other groups in this article, but using the GIPSY / OASIS II software developed at the Jet Propulsion Laboratory. The GIMS survey, done with single-frequency receivers, was analyzed with the Bernese software, which is better equipped than GIPSY to handle single-frequency data. The USGS pre-earthquake data were analyzed by the USGS with the Bernese software, and their solutions compared to the Stanford post-earthquake solutions. More details of the data analysis are given in Freymueller et al. (1994).

The Stanford GIPSY solutions for all dual-frequency L2-codeless data (all data except GIMS) used a global network of about 25 GPS receivers to estimate precise satellite orbits and provide a consistent frame of reference for determining co-seismic displacements. Data from all sites were used simultaneously to estimate station coordinates along with precise satellite orbits for all satellites. Independent solutions were generated for each day of data. The positions of several stations distributed around the globe [Algonquin (Canada), Canberra (Australia), Fairbanks (Alaska), Hartebeesthoek (South Africa), and Kokee (Hawaii)] were constrained with a priori weights of $5 \mathrm{~cm}$. The a priori site positions were based on the Goddard Space Flight Center VLBI model GLB753.

To correct the single-frequency GIMS data, empirical ionospheric models were generated using data from nearby permanent GPS sites (Goldstone, Pinyon, JPL, and 


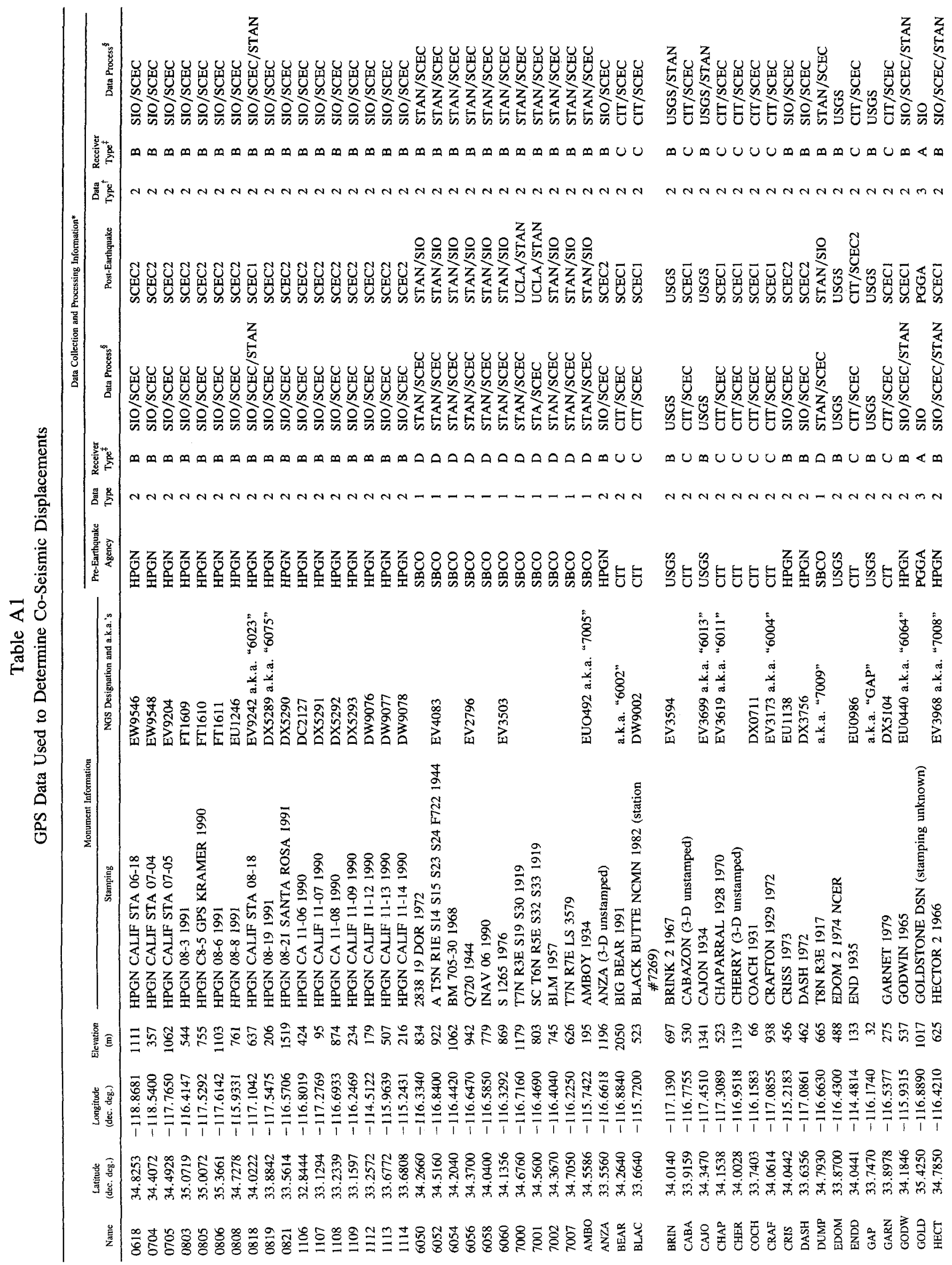




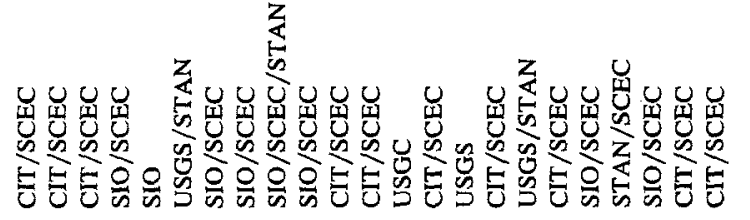

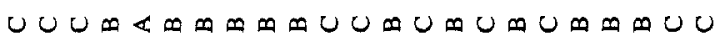

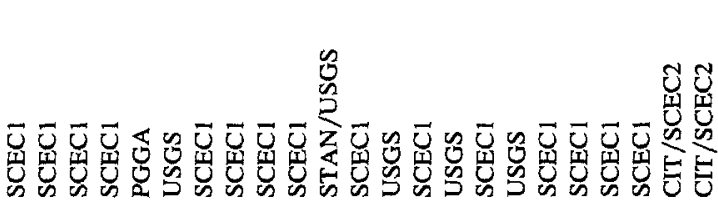

$z \quad \frac{2}{n}$

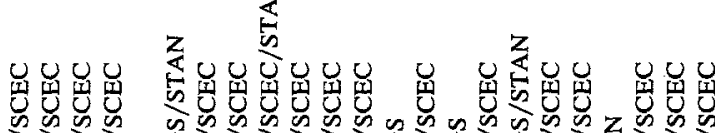

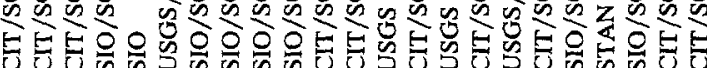

U UUח

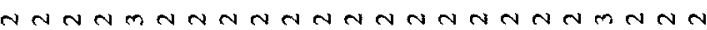

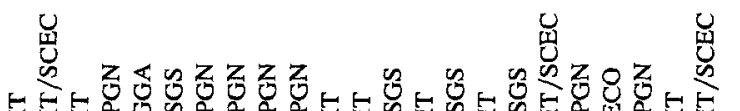

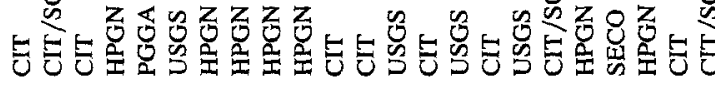

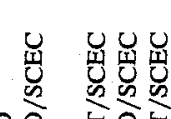
운

$\varangle \infty$

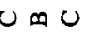

导异

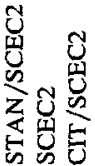

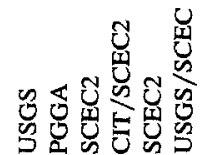

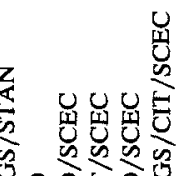

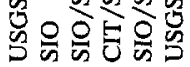

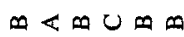

$<\infty$

$\operatorname{man} 4 n$

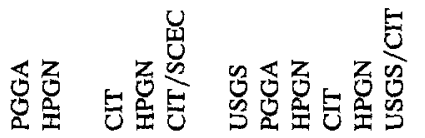

ᄂ 0

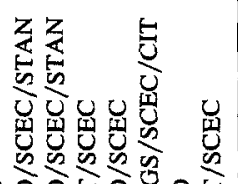

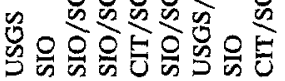

$\infty \ll \oplus \oplus \cup \sqcap \oplus \varangle U$

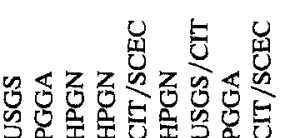

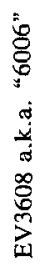

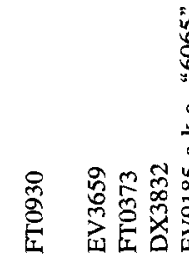

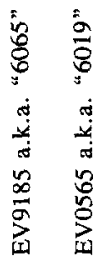

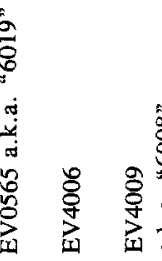

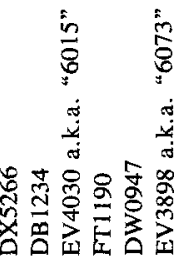

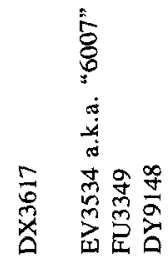

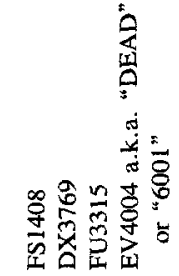

نं

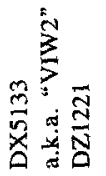

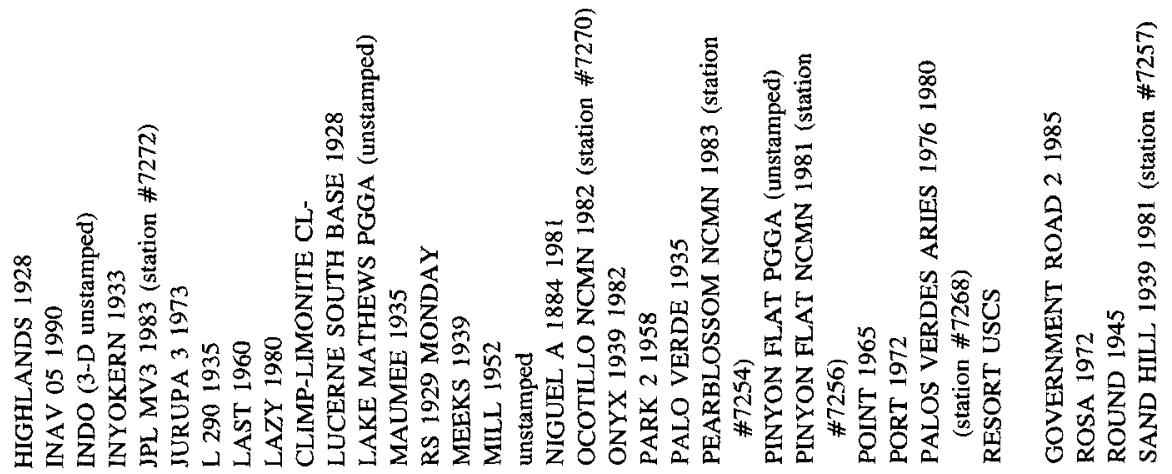

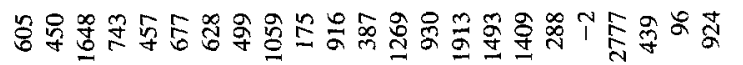

承

ने $2 \%$

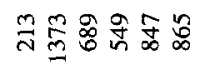

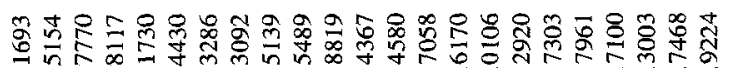

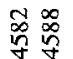

总象

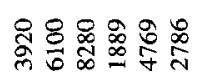

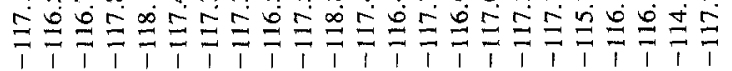

$\stackrel{0}{=}$

$\triangleq \stackrel{\infty}{=}$

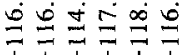

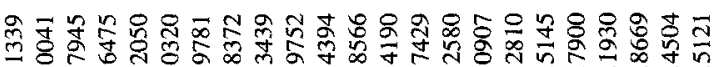

ปิ

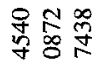

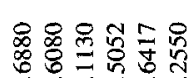

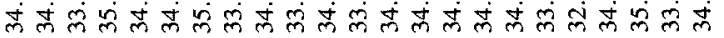

लं लिं

में

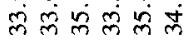

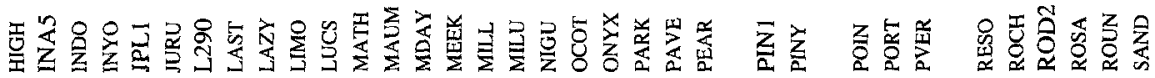

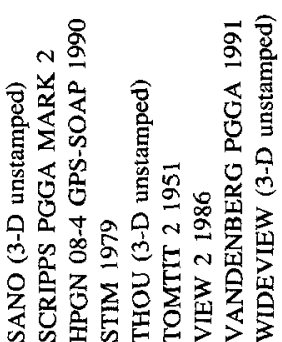

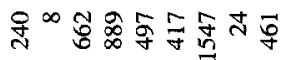

设

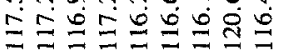

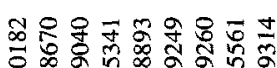

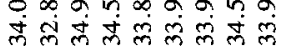

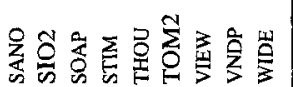

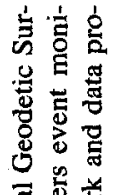

สำ ํㅝㅇ

要紊

焉

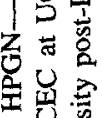

!

莺焉

总言焉

矛苑

客

羊

若

官象

蛋

空前

安年

票导

एठ워

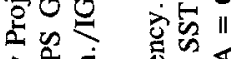

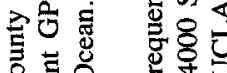

ठำ

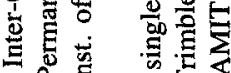

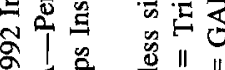

论

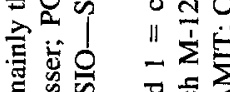

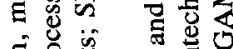

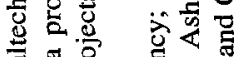

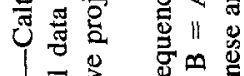

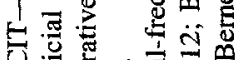

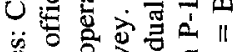

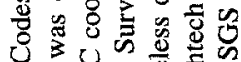
J ज

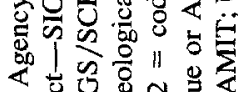
.

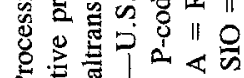

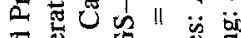
苛

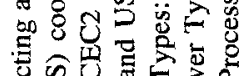
* 
Table A2

USGS Trilateration Station Coordinates

\begin{tabular}{|c|c|c|c|c|c|}
\hline \multirow[b]{2}{*}{ Name } & \multirow{2}{*}{$\begin{array}{c}\text { Latitude } \\
\text { (dec. deg.) }\end{array}$} & \multirow{2}{*}{$\begin{array}{l}\text { Longitude } \\
\text { (dec. deg.) }\end{array}$} & \multirow{2}{*}{$\begin{array}{c}\text { Elevation } \\
\text { (m) }\end{array}$} & \multicolumn{2}{|c|}{ Monument Infornation } \\
\hline & & & & Stamping & NGS Designation \\
\hline \multicolumn{6}{|c|}{ Geodolite Stations } \\
\hline $29 \mathrm{PA}$ & 34.0586 & -115.9514 & 1391 & 29 PALMS 1934 & EU1170 \\
\hline BEAC & 33.9240 & -116.6160 & 527 & BEACON 21974 & \\
\hline BERD & 33.8612 & -116.0890 & 1634 & LITTEL BERDOO 1931 & DX4831 \\
\hline BOUL & 34.5109 & -116.5607 & 1195 & BOULDER 1935 & EV4071 \\
\hline CREO & 34.4291 & -116.3060 & 1351 & CREOLE 1934 & EV4001 \\
\hline DOME & 33.9663 & -116.4494 & 619 & DOME 1932 & DX4887 \\
\hline FLAS & 34.8240 & -117.0167 & 960 & FLASH 19401972 & EV1101 \\
\hline FRY & 34.5012 & -116.7190 & 1321 & FRY 1935 & EV4072 \\
\hline HARV & 34.9350 & -116.6667 & 621 & HARVARD 1957 & EV4065 \\
\hline INSP & 33.9360 & -116.1950 & 1699 & INSP NCER 1977 & \\
\hline KEYS & 34.0826 & -116.1908 & 1366 & KEYS 1939 & EV3987 \\
\hline LAQU & 33.7040 & -116.3127 & 383 & LA QUINTA 1931 & DX4867 \\
\hline LAVA & 34.7758 & -116.7765 & 1465 & LAVA 1954 & EV4107 \\
\hline LEDG & 34.5020 & -116.4391 & 1200 & LEDGE 1935 & EV3958 \\
\hline MEAN & 34,4048 & -116.5489 & 1098 & MEANS 1935 & \\
\hline MESQ & 34.1836 & -116.1134 & 642 & MESQUITE 1939 & EV3978 a.k.a. “6069” \\
\hline OLDW & 34.3887 & -116.7519 & 1229 & OLD WOMAN 1935 & EV4040 \\
\hline ORD & 34.6749 & -116.8151 & 1924 & ORD 1929 & EV4081 \\
\hline PAXN & 34.1530 & -116.3900 & 1159 & PAX NCER 1977 & \\
\hline QUEE & 34.0526 & -116.0971 & 1730 & QUEEN 1939 & EV3986 \\
\hline RICH & 34.2641 & -116.4689 & 1309 & RICH 1939 & EV4005 \\
\hline ROCK & 34.5441 & -116.7706 & 1194 & ROCK 1935 & EV4082 \\
\hline SEGR & 34.3150 & -116.0780 & 1062 & SEGUNDO 1939 RESET 1978 & \\
\hline SEGU & 34.3147 & -116.0791 & 1062 & SEGUNDO 1939 & EV3975 \\
\hline STUB & 33.9540 & -116.7740 & 933 & STUBBE 1974 NCER & \\
\hline TRAM & 33.8700 & -116.5590 & 207 & & \\
\hline VALM & 34.2183 & -115.9691 & 704 & VALLEY MT MWD ECC 1939 & EU1174 \\
\hline WARR & 34.0551 & -116.4071 & 1555 & WARREN 1939 & EV3994 \\
\hline \multicolumn{6}{|c|}{ Two-Color Stations } \\
\hline GREEN & 33.5743 & -116.4456 & & Green (instrument station) & \\
\hline pf1 & 33.5839 & -116.4289 & & pf1 & \\
\hline pf2 & 33.5985 & -116.4365 & & $\mathrm{pf} 2$ & \\
\hline pf2a & 33.5931 & -116.4379 & & $\mathrm{pf} 2 \mathrm{a}$ & \\
\hline pf $2 b$ & 33.5985 & -116.4371 & & $\mathrm{pf} 2 \mathrm{~b}$ & \\
\hline pf3 & 33.6015 & -116.4460 & & pf3 & \\
\hline $\mathrm{pf} 3 \mathrm{c}$ & 33.6123 & -116.4570 & & $\mathrm{pf} 3 \mathrm{c}$ & \\
\hline rush & 33.6102 & -116.4566 & & rush & \\
\hline pf $4 a$ & 33.6121 & -116.4602 & & $\mathrm{pf} 4 \mathrm{a}$ & \\
\hline pf5 & 33.6030 & -116.4760 & & pf5 & \\
\hline pf6 & 33.5804 & -116.4905 & & pf6 & \\
\hline sugar & 33.5851 & -116.4477 & & sugar & \\
\hline asbestos & 33.6205 & -116.4609 & & asbestos & \\
\hline TABLE & 33.5271 & -116.5882 & & Table (instrument station) & \\
\hline tule & 33.4419 & -116.6162 & & tule & \\
\hline terwil & 33.4906 & -116.6695 & & terwil & \\
\hline red & 33.5206 & -116.5110 & & red & \\
\hline rosa & 33.5503 & -116.5461 & & rosa & \\
\hline roadcut & 33.5678 & -116.5940 & & roadcut & \\
\hline radio & 33.5793 & -116.6228 & & radio & \\
\hline OPENVW & 33.5982 & -116.6442 & & Openvw (instrument station) & \\
\hline bull & 33.5832 & -116.5687 & & bull & \\
\hline scrunge & 33.6506 & -116.5910 & & scrunge & \\
\hline fobes & 33.6484 & -116.6336 & & fobes & \\
\hline cravens & 33.5427 & -116.7002 & & cravens & \\
\hline howy & 33.5496 & -116.7166 & & howy & \\
\hline cary & 33.5443 & -116.7348 & & cary & \\
\hline anza & 33.5591 & -116.6297 & & anza & \\
\hline cravens & 33.5427 & -116.7002 & & cravens & \\
\hline LIME & 34.4583 & -117.8444 & & Lime (instrument station) & \\
\hline llano & 34.4988 & -117.8180 & & Ilano & \\
\hline
\end{tabular}


Table A2-Continued

\begin{tabular}{llllll}
\hline \multicolumn{1}{c}{ Name } & $\begin{array}{c}\text { Latitude } \\
\text { (dec. deg.) }\end{array}$ & $\begin{array}{c}\text { Longitude } \\
\text { (dec. deg.) }\end{array}$ & $\begin{array}{c}\text { Elevation } \\
\text { (m) }\end{array}$ & & Stamping \\
\hline largo & 34.4650 & -117.7836 & Monument Information & NGS Designation \\
calef & 34.4050 & -117.7882 & calef & \\
pinyon & 34.4123 & -117.8077 & pinyon & \\
punch & 34.4135 & -117.8589 & punch & neefus \\
neefus & 34.4417 & -117.8729 & ward & swan \\
ward & 34.4916 & -117.9182 & lewis \\
swan & 34.4699 & -117.8783 & bird \\
lewis & 34.4160 & -117.8824 & lepage \\
bird & 34.4323 & -117.9222 & bigrock \\
lepage & 34.4491 & -117.9052 & Buttes (instrument station) \\
bigrock & 34.5065 & -117.8530 & sand \\
BUTTE & 34.6815 & -117.7218 & monday \\
sand & 34.6147 & -117.7567 & mirage \\
monday & 34.7429 & -117.7035 & adobe \\
mirage & 34.7149 & -117.7052 & east \\
adobe & 34.6955 & -117.6814 & hansen \\
east & 34.6525 & -117.6690 & hivista \\
hansen & 34.6295 & -117.6940 & park \\
hivista & 34.7347 & -117.7602 & saddle \\
park & 34.6809 & -117.7571 & yucca \\
saddle & 34.6570 & -117.7654 & bluerock \\
yucca & 34.6397 & -117.7819 & moody \\
bluerock & 34.7023 & -117.8214 & playa \\
moody & 34.6105 & -117.6874 & -117.7995 & \\
playa & 34.7296 & &
\end{tabular}

Scripps). The relative ionospheric delays determined from these sites were used to estimate coefficients for a polynomial expansion of the ionospheric path delay as a function of position and time (Georgiadou and Kleusberg, 1988). A different model was generated for each 1- to 3-hr observation session. Application of the ionospheric corrections improved the internal repeatability of the GIMS network by roughly $50 \%$. Even so, the precision of the pre-earthquake positions for these stations is relatively low (compared with dual-frequency results), with the best determined to about $3 \mathrm{~cm}$ and most to about $5 \mathrm{~cm}$ in horizontal components. The precision is limited both by the short observation sessions and by the inability of the ionospheric model to remove all of the path delay. These data are inherently noisier than the more precise dual-frequency data.

Bernese Dual-Frequency Solutions. The USGS group performed broadcast and improved orbit solutions of their own dual-frequency L2-codeless GPS data from 6-hr sessions on their Coachella and Cajon monitor nets, selected sites of Joshua Tree network, and also the postearthquake reoccupation of the Mojave geodolite, or electro-optical distance measurement (EDM) network. These Bernese solutions were used for several purposes in this article. First, as in Murray et al. (1993), the Mojave network postseismic data were obtained by this method. Also, these Bernese results were used for pre- earthquake solutions in the case of some displacement vectors analyzed by the Stanford group.

\section{GPS Data Processing Particulars}

UCLA Group Particulars. The UCLA group analyzed pre- and post-earthquake GAMIT solution files by simultaneous least-squares inversion of many daily solutions, using the FONDA software (Dong, 1993). The leastsquares solution obtained the pre-earthquake station positions and the co-seismic displacements. Covariances of the interstation vectors are taken into account in the inversion process. Vertical components were not estimated.

Scripps Group Particulars. The Scripps group analyzed the pre- and post-Landers California HPGN data with reference to and in combination with the PGGA stations in southern California and the global tracking stations of the International GPS Service for Geodynamics (e.g., Bock et al. 1993a, b). Data from many individual daily GAMIT solutions were combined using the Kalman filter-based network adjustment program GLOBK (Herring et al., 1990; Bock et al., 1994).

Stanford Analysis Particulars. Coordinates from all of the GIPSY and Bernese solutions were adjusted together to form complete, consistent sets of pre- and postearthquake coordinates. The two sets of coordinates were dif- 
ferenced to produce the displacements. To avoid the problem of correcting for global plate motions, only solutions from late June 1992 were used in the pre-earthquake adjustment for the sites outside of California. The covariance of the coordinates were scaled so that the reduced chi-square statistic was unity. Prior to scaling, the reduced chi-square statistic (for the global solutions) was typically in the range of $(2 \text { to } 2.5)^{2}$, indicating that the formal uncertainties on a global scale were underestimated by a factor of 2 to 2.5 . The covariance of the single-frequency GIMS survey was scaled by a factor of about $8^{2}$, a result of the ionospheric errors which remain in that data set.

USGS Analysis Particulars. The pre- and post-earthquake daily GAMIT solution files were used in analysis by the USGS. For stations labeled USGS-G in Table 1, data from many individual daily GAMIT solutions were combined using the Kalman filter-based network adjustment program GLOBK (Herring et al., 1990). Preand post-earthquake solutions obtained from bias-fixed GAMTT solutions were compared using the BCSUM module of the GLOBK software. For the few stations labeled USGS-O in Table 2, interstation vector baseline components were combined for pre- and post-earthquake time intervals and then differenced, but without performing a readjustment of the data. Errors were combined by summing squares, and the resultant error estimates were tripled in each component in order to approximate repeatability. For these stations, an assumed factor of 3 scaling was based on comparisons of GAMIT solution formal errors with observed daily repeatability in the PGGA data (i.e., Bock et al., 1993a, b).

Trilateration Data Analysis. Displacements were recomputed from the trilateration data of Murray et al. (1993), incorporating two minor changes. First, corrections were made for the secular deformation of the Mojave network for the time interval 1982.5 through 1992.8, based upon earlier trilateration and triangulation surveys' determination of the pre-earthquake secular strain rate (Table 3). The Mojave EDM network spans the Homestead segments of the Landers rupture zone (Fig. 1). Most of these lines are west of the rupture. The USGS observed the lines of the western Mojave network twice, with EDM in 1982.5 and with GPS in 1992.8 (L2-codeless, dual-frequency Ashtech receivers and 6-hr sessions; Bernese postprocessing). Sauber et al. (1986) used triangulation and EDM data to calculate the 1934 to 1982 deviatoric strain rate for the western Mojave network. The principal strain rates (with maximum and minimum rates necessarily equal) are $0.08 \pm 0.02$ and $-0.08 \pm$ 0.02 microstrain per year, with the axis of maximum strain oriented $N 86^{\circ} \mathrm{W} \pm 5^{\circ}$. We assume that these results describe the secular deformation, and use them to estimate the secular correction for each line of the west- ern Mojave network. For the time interval between the two USGS surveys, the principal strain rates predict that lines parallel to the maximum or minimum axis should change by approximately +0.8 or -0.8 parts per million. The estimated secular strain corrections range from near zero to over twice the standard error in a given length change, so in several cases these corrections are important. Most of the predicted secular changes are less than $1 \mathrm{~cm}$. The largest is a $2.12-\mathrm{cm}$ contraction for LUCS-ORD, the longest line $(26.8 \mathrm{~km})$ of the western Mojave network. For each line, we subtracted the estimated secular correction from the observed change. The remaining signal we term the "estimated" co-seismic deformation associated with the Landers earthquake.

Second, we computed displacement vectors from the trilateration line-length changes using our estimates of co-seismic displacements from the GPS data at stations SAND, MAUM, MEEKS, and EDOM (Table 2). Because these co-seismic vectors are from the jointly analyzed GPS results, constraining the trilateration results with these vectors also places the trilateration-based displacement vectors in the same reference frame as the GPS co-seismic vectors. It is preferable to use the trilateration data in their original form (colinear length change and error) as input data to any modeling or data analysis program. These recalculated displacements may be useful for those who need, or prefer, to use data in the form of displacements, as is sometimes the case (e.g., Wald and Heaton, 1994).

Two-Color Laser Data and Analysis. The USGS measures line lengths at four other networks in southern California using a two-color geodimeter (Slater and Huggett, 1976; Langbein et al., 1987; Langbein, 1989). These measurements have a nominal precision of 0.1 to 0.2 ppm and have detected co-seismic displacements of the order of $1 \mathrm{ppm}$ on some baselines located approximately $100 \mathrm{~km}$ from Landers. The baseline lengths in the four networks, Pearblossom, Buttes, Pinon, and Anza, are usually measured between two and four times annually. To estimate the co-seismic displacements on each of the 45 baselines, a three-parameter regression of the form $D_{i}=M^{*} t_{i}+B+C$ has been fit to the measured line lengths, where $D_{i}$ is the distance measured at time $t_{i}, M$ is the secular rate, $B$ is the nominal distance, and $C$ is the co-seismic offset. Our estimates of $C$, the co-seismic offsets, are shown in Table 5. In general, the secular strain measured at these four locations show nearly pure shear of the order of $0.2 \mathrm{ppm} / \mathrm{yr}$ or less.

Our measurements from the Pearblossom and Pinon networks closely span the co-seismic interval with measurements in late May and early July 1992. For both Anza and the Buttes, our preseismic survey was made in February 1992, and the first postseismic surveys occurred in July 1992 for Anza and in October 1992 for Buttes. 
Although we have measurements of line lengths since 1980 for Pearblossom (Langbein et al., 1982), we have used the observations since 1986 because of changes in the instrumentation and network configuration at that time. This 12 baseline network, which straddles the San Andreas fault near Palmdale, is measured three to four times annually, yielding better-determined estimates of coseismic offsets than those networks measured less frequently. At Pinon, our measurements commenced in 1986 for this 8 baseline network near the Pinon Flat Observatory. Analysis of this network is complicated by the fact that commencing in May 1992, we started using a second, newer, monument at GREEN. We occupied both monuments at GREEN in May 1992, but the postearthquake surveys used only the second monument. To estimate secular rate and the co-seismic offset, an additional parameter, owing to the distance offset from the second monument, was used in the regression. The 13 baseline network at Anza is measured twice annually and commenced in late 1988. This network is within 20 to $30 \mathrm{~km}$ from the Pinon network and is used to study strain accumulation across the San Jacinto fault. Finally, the 12 baseline Buttes networks is located approximately 40 to $50 \mathrm{~km}$ from the Pearblossom network and is used to study possible strain accumulation in the Mojave desert in an area with no recent fault movement. Since there are only three measurements of this network since its initial occupation in early 1991, the co-seismic offsets have a higher statistical uncertainty than those from the other networks.

U.S. Geological Survey

Pasadena, California 91106

(K.H.)

U.S. Geological Survey

Menlo Park, California 94025

(M.L., K.G., N.K., J.L., J.S.)

Lawrence Livermore National Lab

Livermore, California 94550

(S.L.)

Department of Earth and Space Sciences

UCLA

Los Angeles, California 90024

(M.C., Y.F., X.G., D.J., M.K., Z.S.)

I.G.P.P.

Scripps Institution of Oceanography

UCSD, La Jolla, California 92093

(Y.B., P.F., J.Z.)

Department of Geological Sciences

Stanford University

Stanford, California 94305

(J.F.)

Manuscript received 29 July 1993. 